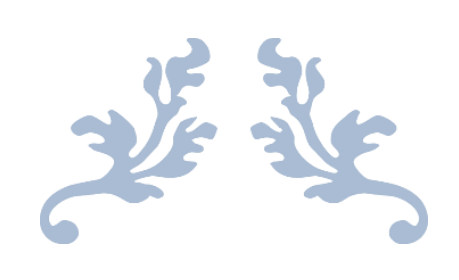

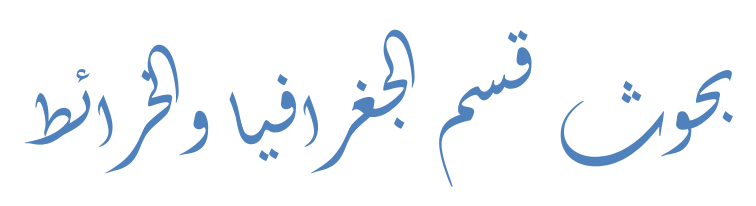

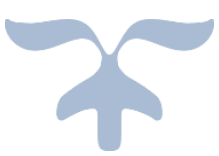




\section{GIS-Based for Mapping Malaria Risk under geographical Factors in the Nile Basin Countries}

$$
\text { د/حسن حسونة }
$$

يعتمد على نظام المعلومات الجغرافية لرسم خرائط مخاطر الملاريا تحت العوامل الجغرافية في

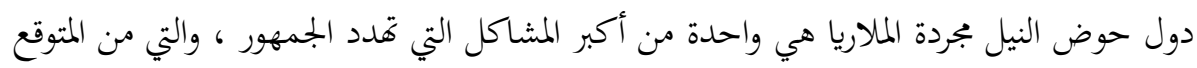

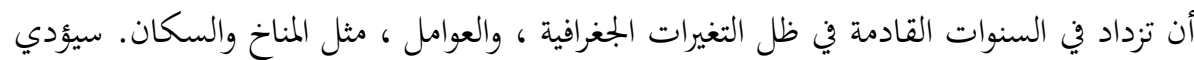

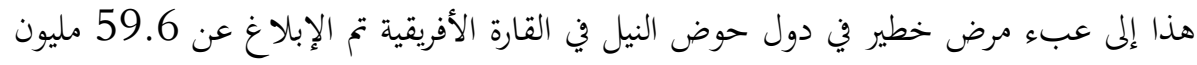

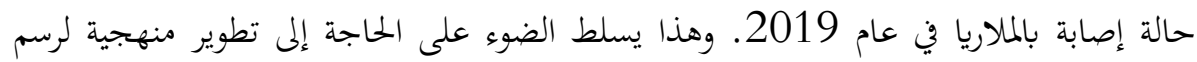

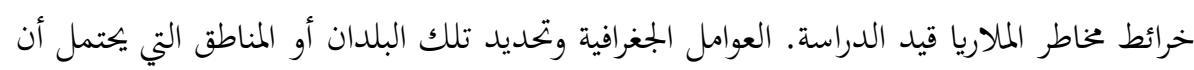

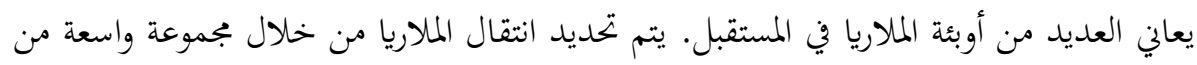

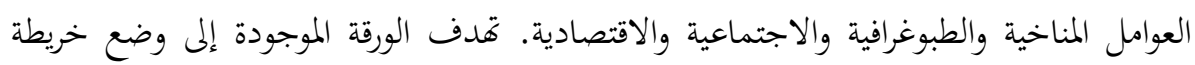

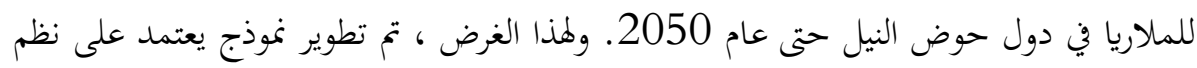

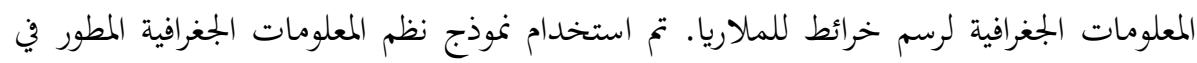
رسم خرائط مخاطر الملاريا تحت عوامل جغرافية مختلفة تم التحقق من صحة خراتط خريطة المخاطر النابتحة مقارنة بييانات مراضة الملاريا في دول حوض النيل على مستوى المنطقة الصحية. أخيرًا ، تم

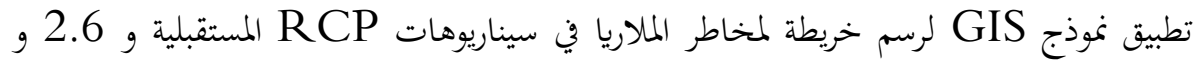

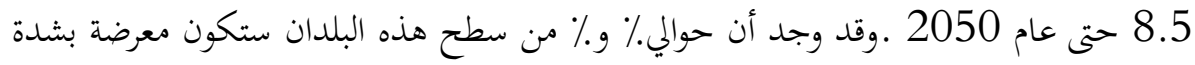

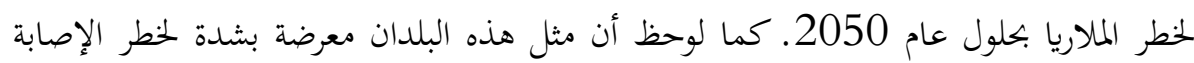

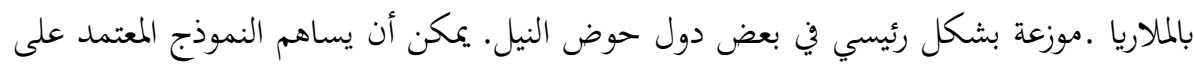

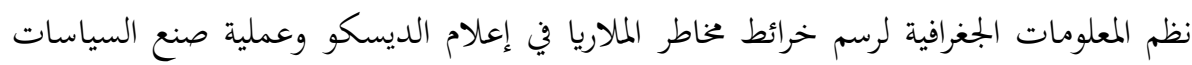

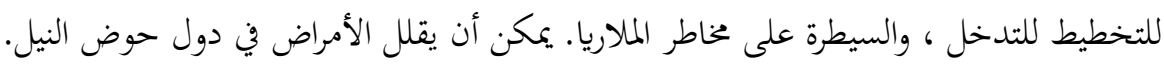




\section{Abstract}

Malaria is one of the greatest problems threating public, which is expected to increase in the coming years under, the changes of geographical, factors, such as the climate and population. This will execrable disease burden in the Nile basin countries in African continent 59.6 million cases of malaria were reported in 2019. This highlights the need for developing a methodology for mapping malaria risk under studying. The geographical factors and delineating those countries or regions that many potentially experience malaria epidemics in the future. Malaria transmission determined by a wide range of climatic, Topographic and Socioeconomic factors. The paper in hand is intended to map malaria in the countries of the Nile basin up to 2050. For this purpose, a GIS based model was developed for mapping malaria. The developed GIS-model was used in mapping malaria risk under different geographical factors produced risk map was validated compared to malaria morbidity data in the basin Nile countries at health district level. Finally, the GIS-model was applied to map malaria risk in the future RCP, 2.6 and 8.5 scenarios up to 2050.

It was found that about\% and \%these countries land surface will be highly vulnerable to malaria risk by 2050 . Also it was noted that such highly vulnerable are.

Distributed mainly in some Nile basin countries. The suggested GIS based model for mapping malaria risk can contribute to inform discoing and policy making process of 
planning for intervention, control malaria risk. That can reducing disease in the Nile basin countries.

\section{Key words}

Malaria, GIS, Mapping vulnerability, confirmed cases, falciparum.

\section{Introduction:}

Malaria represents one of the largest problems threating global public health with total exceed 228 million occurred worldwide in 2018 (95\%). Confidence interval (ci) 206-258 million and compared with 251million cases in 2010 (96\%) (ci) 231-279 million) and 231 million cases in 2017 (95\%) (Ci) 211-259 million.

Most Malaria cases in 2018 were in African Region (213 million or 93\%) according to Who, followed by the WHO south east Asia Region with 3,4\% and the eastern Mediterranean regions with $2,1 \%$.

Nineteen countries in sub Saharan African and India carried almost $85 \%$ of the global malaria burden. Six countries accounted for more than half of all malaria cases worldwide: Nigeria (25\%), The Democratic Congo (12\%), Uganda $5 \%$ and there three countries such as Cote-devoir, Mozambique and Niger (4\% each). The observable the incidence rate of malaria declined between 2010 and 2018 from 71 to 57 cases per 10000 population and the rate declined also to $22 \%$. 
In 2018 there were 405000 deaths from the globally compared with 585000 in 2010. Most deaths were from children aged under 5 years old who affected by malaria that accounted to 67\% (272000) person of the deaths from malaria. Most of the deaths from Africa Region mealy $95 \%$ of all malaria deaths in 2018 and they concentrated in 20 countries, Nigeria came in the first rank $74 \%$ followed by Republic Conge 11\%, Tanzania 5\% and there four countries $4 \%$ per each.

Many researches interested in recognizing the geographical factors that may help in spreading Malaria risk in countries of the Nile basin. The existence of climate in Malaria transmission was very obvious, and the connection between epidemics of Malaria and climate was evidence in various regions worldwide especially in Nile basin countries and Sub - Saharan African countries. Where the higher temperature may a reason of malaria incidence because it contributes to shortening extrinsic incubation period of anopheles mosquito (Olsen, 2009, p.6).The optimum temperature for Anopheles mosquito for breeding ranges between $20^{\circ} \mathrm{c}$ and $30^{\circ} \mathrm{c}$. Also malaria connected with wet condition such as rainfall and relative humidity which can help anopheles mosquito to breed and complete its life cycle. Malaria incidence is impacted by topographic factor such as altitude, slope, and vegetation. In the high altitude decreases parasite development and prevent the spread of malaria. There are another geographical factor like the social environments that represented in population density, housing, deforestation, Dams, the agricultural craft, 4 
urbanization and population movement. All these geographic factors help in the spread of malaria in the Nile basin countries.

Malaria is considered one of the main health issues in the Nile basin countries in term of morbidity and mortality and connected sever economic cost. In 2019 the Nile basin counters had 71 million estimated cases of malaria and 80870 deaths. The paper is hand is intended to map malaria risk in the Nile basin countries under many geographical factors change up to 2050.for this purpose, a GIS- based will be devolved for mapping malaria through the geographical factors. The spatial variations of the considered determinants are used to predict those areas of high malaria risk under expected geographical factors.

II the social Environmental the human geography may impacted by malaria from following the next points.

\section{Malaria in Egypt}

The present distribution cases in Egypt as reported by Ministry of Health is demonstrated in table (1) and fig. (1).

- Egypt has 85201 Malarias cases in 1960 most of the patients from the infection of the mosquito of plasmodium vivax that grow in Egypt that equal $97.7 \%$ of the confirmed cases.

- The number of malarias cases has decreased to 23 cases in 2015 with a decreasing rate equal 9907.3\% in comparison with 1995 as a result of the government 
efforts in medical care and most of discovered malaria refers to infection acquired outside and brought in Egypt.

So the researcher is excluded Egypt from the Nile basin countries because of Egypt has no Malarias cases in recent years.

Table (1) Malaria in Egypt from 1960-2019

\begin{tabular}{|l|l|l|l|l|l|}
\hline Year & $\begin{array}{l}\text { Confirmed } \\
\text { Malaria }\end{array}$ & $\begin{array}{l}\text { Plasmodium } \\
\text { vivax }\end{array}$ & $\%$ & $\begin{array}{l}\text { Plasmodium } \\
\text { falciparum }\end{array}$ & $\%$ \\
\hline 1960 & $\mathbf{8 5 2 0 1}$ & $\mathbf{8 3 2 0 5}$ & $\mathbf{9 7 . 7}$ & $\mathbf{1 9 9 6}$ & $\mathbf{2 . 3}$ \\
\hline 1965 & $\mathbf{7 9 9 7}$ & $\mathbf{7 8 5 3}$ & $\mathbf{9 8 . 2}$ & $\mathbf{1 4 4}$ & $\mathbf{1 . 8}$ \\
\hline 1975 & 1805 & 1759 & $\mathbf{9 7 . 4}$ & $\mathbf{4 6}$ & $\mathbf{2 . 6}$ \\
\hline 1985 & $\mathbf{7 2}$ & $\mathbf{5 3}$ & $\mathbf{7 3 . 6}$ & $\mathbf{1 9}$ & $\mathbf{2 6 . 4}$ \\
\hline 1995 & $\mathbf{3 1 3}$ & $\mathbf{1 5}$ & $\mathbf{4 . 8}$ & $\mathbf{2 9 8}$ & $\mathbf{9 5 . 2}$ \\
\hline $\mathbf{2 0 0 5}$ & $\mathbf{0}$ & $\mathbf{0}$ & $\mathbf{0}$ & $\mathbf{0}$ & $\mathbf{0}$ \\
\hline $\mathbf{2 0 1 5}$ & $\mathbf{2 3}$ & $\mathbf{2}$ & $\mathbf{8 . 7}$ & $\mathbf{2 1}$ & $\mathbf{9 1 . 3}$ \\
\hline $\mathbf{2 0 1 9}$ & $\mathbf{0}$ & $\mathbf{0}$ & $\mathbf{0}$ & $\mathbf{0}$ & $\mathbf{0}$ \\
\hline
\end{tabular}

Source: - Ministry of Health, Egypt, several years. 


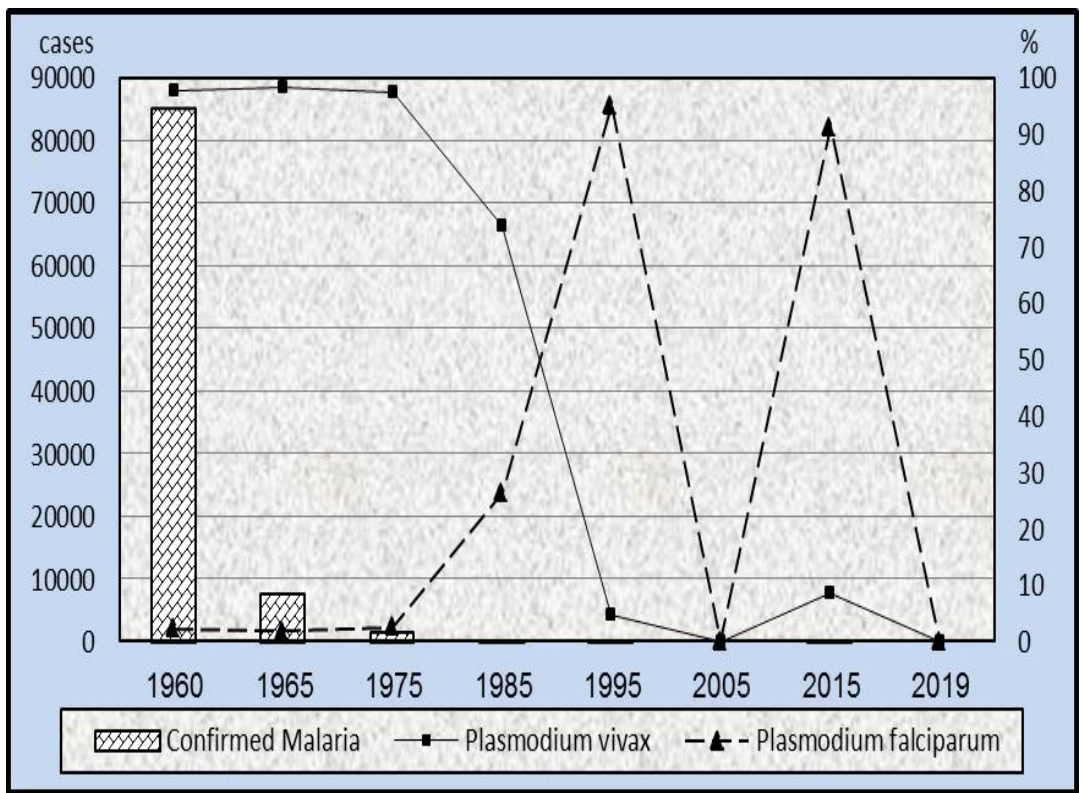

Figure (1)

\section{Environmental factors that causes malaria:}

The environmental factors or habitat factor in the human ecology that effect of the existence of malaria in the Nile basin based on the effect of the natural and environment on the host, the vector and incidental infection. Recent and previous studies have identified a big rang of physical and environmental factors that affect the rate of incidence of malaria such as climate, temperature and rainfall, slop land use and that impact on the biotic environment in the region. The physical or natural environmental factors that have shown to affect the incidence of malaria include water, vegetation cover, and slope of land. 
The last portion of environmental factors is the social environment that include as the same of population factors such as population density, race, age and socio-economic these factors have been shown to share to the incidence of malaria through population density.

I. The physical environment factors:

Geographical location Contain climate elements, highland, floods and the Nile River.

II. The social environmental:

Include deforestation, dam, agriculture, and urbanization and population movement.

III. The development of malaria.

IV. The kind of malaria mosquitoes.

V. The social characteristics of the infected people.

VI. The impacts of malaria.

\section{I - the physical environment factors:}

1-1 Geographical location

The basin Nile counties is located between $3^{\circ}, 30$ south to $31^{\circ}-36$ north covering a total area of 8,9 million $\mathrm{km}$. These countries became populated countries estimated total population size of 576 million inhabitants in 2019. Where \begin{tabular}{l|l} 
urban population represents only about $\%$ of the total \\
\hline 8
\end{tabular} 
population. The Nile basin has a various geographical surface such as mountains, plateaux with an average altitude of $1500 \mathrm{~m}$ and plains. This radiation of the surface has impact on temperature. The south countries of Nile basin countries plus to Ethiopia receives heavy rains compared too little rain in north of the Nile basin. The equator passes in the south of the region and Capricorn of cancer in the middle the make the climate is the optimal environment to grow of falciparum that transmit malaria to the population.

\section{1-2 Climate element and Malaria:}

\section{1- 2-1 Temperature:}

Tropical Nile basin countries, that have temperature between 20-30 centigrade and relative humidity of $60-70 \%$ provide optimum conclusion for malaria transmission. This implies that understanding the malaria dynamic in these countries (requires understanding its correlation with temperature and rainfall (Bruce Chwatt J.I, 1985 p.22).

From the table (2) and fig. (2) That show temperature in the basin Nile countries, we can notice the following:

- The temperature in the basin Nile countries is range between 21-26 that represent the optimal condition for the growth and transmission of malaria. 
GIS-Based for Mapping Malaria Ris... العدد الثامن والثلاثون

Table (3) average temperature $\mathrm{C}^{0}$ between 2008 to 2018 in the countries of the Nile Basin

\begin{tabular}{|l|l|l|l|l|l|l|l|l|l|l|l|}
\hline Countries & 2008 & 2009 & 2010 & 2011 & 2012 & 2013 & 2014 & 2015 & 2016 & 2017 & 2018 \\
\hline Burundi & 21 & 21 & 22 & 22 & 23 & 23 & 24 & 23 & 23 & 22 & 22 \\
\hline Kenya & 23 & 23 & 23 & 25 & 24 & 24 & 23 & 25 & 25 & 21 & 21 \\
\hline Rwanda & 20 & 20 & 21 & 21 & 22 & 22 & 21 & 20 & 20 & 19 & 19 \\
\hline Tanzania & 24 & 24 & 24 & 24 & 25 & 25 & 24 & 24 & 23 & 22 & 23 \\
\hline $\begin{array}{l}\text { D. } \\
\text { Congo. }\end{array}$ & 24 & 25 & 23 & 23 & 25 & 26 & 24 & 25 & 25 & 23 & 22 \\
\hline Ethiopia & 23 & 24 & 26 & 24 & 24 & 26 & 25 & 23 & 22 & 22 & 21 \\
\hline Eretria & 23 & 22 & 21 & 20 & 22 & 23 & 22 & 23 & 22 & 21 & 21 \\
\hline Uganda & 25 & 25 & 24 & 24 & 25 & 25 & 23 & 23 & 24 & 22 & 22 \\
\hline S. Sudan & 23 & 24 & 24 & 23 & 24 & 25 & 23 & 24 & 23 & 23 & 24 \\
\hline Sudan & 21 & 21 & 22 & 22 & 23 & 23 & 22 & 21 & 22 & 22 & 21 \\
\hline
\end{tabular}

Source: East African community (EAC) facts and figures 2019.

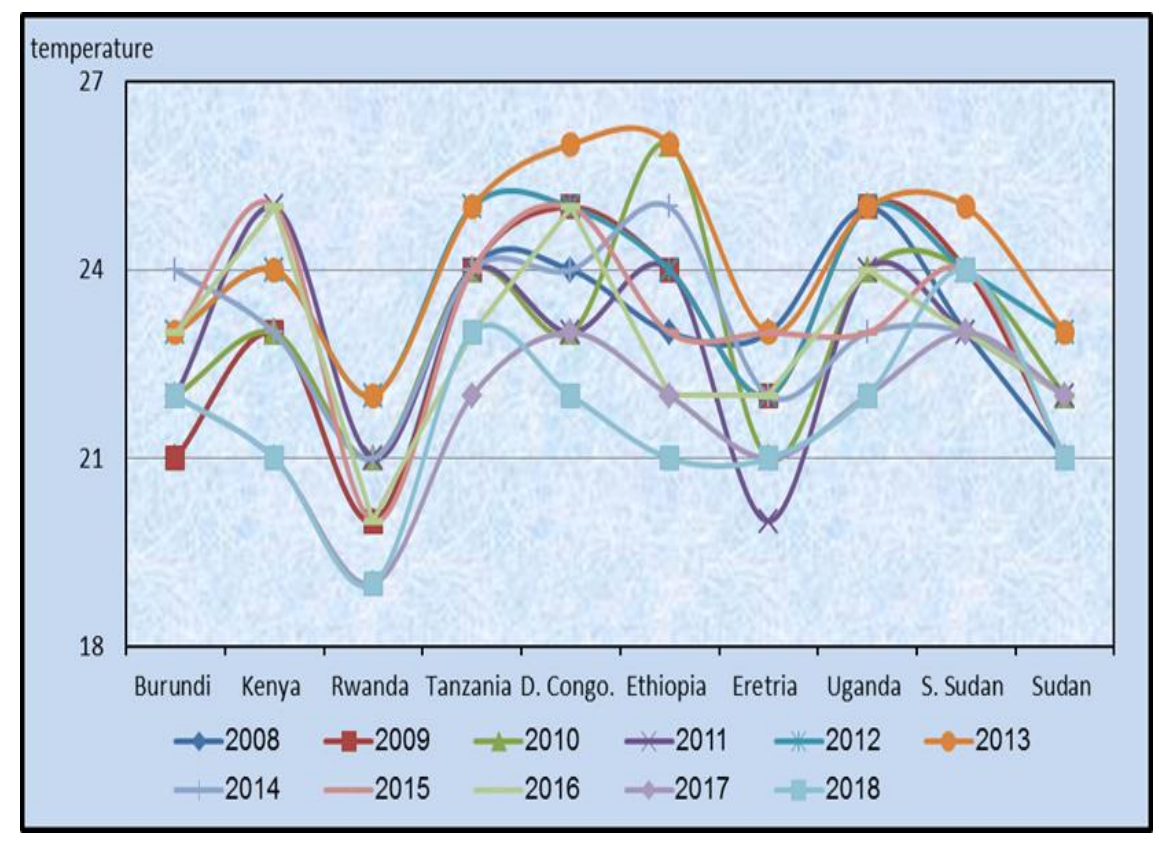

Figure (2) 


\section{1-2-2 The impact of the temperature on the} transmission of malaria.

Temperature plays an important part in the survival of the parasites in the anopheles mosquito vector. Because of these parasites have a short development cycle that lasts between 7 to 21 days. The parasites need an optimum temperature ranging between $27-31{ }^{\circ} \mathrm{C}$ (Graig, 1994, p.105) on contrary the temperature below $20^{\circ} \mathrm{c}$ does not favor the plasmodium falciparum species to complete their cycle growing and transmission of the disease.

The tropical climate in the basin Nile with their average annual temperature ranging from $18^{0} \mathrm{c}$ to $37^{0} \mathrm{c}$ provide the best environment to complete the cycle of plasmodium falciparum spices ant transmitted malaria in the population.

Temperature and rainfall are assumed in the role of the malaria transmission. The rainfall affect in the mosquito larva habitat (Zhou G, 2004, p 107).

Maximum monthly temperature affects variation in monthly malaria incidence.

\section{1-2-3 Temperature and falciparum}

The development of p. falciparum is rely on temperature. The great temperature range for parasite growth in the female anopheles in between $25^{\circ} \mathrm{c}$ and $30^{\circ} \mathrm{c}$. 
Low temperature delay female anopheles growth especially in the period of term its infective bite.

About $35^{\circ} \mathrm{c}$ female anopheles slowdown. High temperature also connected with the development of smaller adult mosquitoes at the temperature, $40^{\circ} \mathrm{c}$ to $42^{\circ} \mathrm{c}$ death of mosquitoes happen certainly. Maximum temperature is of the greatest factors predict of the mosquito survival and completion of their life cycle.

\section{2 rainfall:}

Rainfall plays an important role in malaria growth and transmission because of its impact on the mosquito larva life cycle. The table (3) show the average monthly rainfall in these countries.

Table (3)Average monthly rain fall of the Nile basin countries (mm/month)

\begin{tabular}{|l|l|l|l|l|l|l|l|l|l|l|l|l|}
\hline Country & Jun. & Feb. & Mar. & Apr. & May & Jun. & Jul. & Aug. & Sep. & Oct. & Nov. & Dec. \\
\hline Burundi & 16 & 85.7 & 117.5 & 111.9 & 56.6 & 8.9 & 2.7 & 13.4 & 33.2 & 59.1 & 97.1 & 100 \\
\hline Kenya & 44.1 & 56.7 & 93 & 1219.5 & 179 & 35 & 40.5 & 39.5 & 39 & 79 & 154.3 & 108 \\
\hline Rwanda & 77 & 91 & 114.2 & 154.2 & 88.1 & 18.7 & 11.5 & 31.1 & 70 & 106 & 113 & 77.4 \\
\hline Tanzania & 133.9 & 145 & 114 & 58 & 5.3 & 0.1 & - & - & - & 2.1 & 26.3 & 123.3 \\
\hline Uganda & 68.4 & 64 & 131.5 & 170 & 118 & 70 & 63.1 & 96 & 108.4 & 138 & 149 & 92 \\
\hline $\begin{array}{l}\text { D. } \\
\text { Congo }\end{array}$ & 41 & 49 & 82 & 177 & 139 & 114 & 159 & 193 & 109 & 45 & 73 & 53 \\
\hline Ethiopia & 80 & 110 & 401 & 855 & 1078 & 1152 & 1937 & 197 & 2241 & 1630 & 90 & 52 \\
\hline Eretria & 31 & 30 & 44 & 65 & 69 & 60 & 40 & 39 & 38 & 22 & 24 & 21 \\
\hline S. Sudan & 41 & 42 & 79 & 120 & 110 & - & 60 & 76 & - & 101 & 78 & 60 \\
\hline Sudan & 40 & 43 & 65 & 30 & 24 & - & - & - & 22 & 23 & 30 & 50 \\
\hline
\end{tabular}

Source : 1- world meteorological organization (WMO) 2019. 
2-National governments of Ethiopia, Sudan and Sudan, December, 2019.

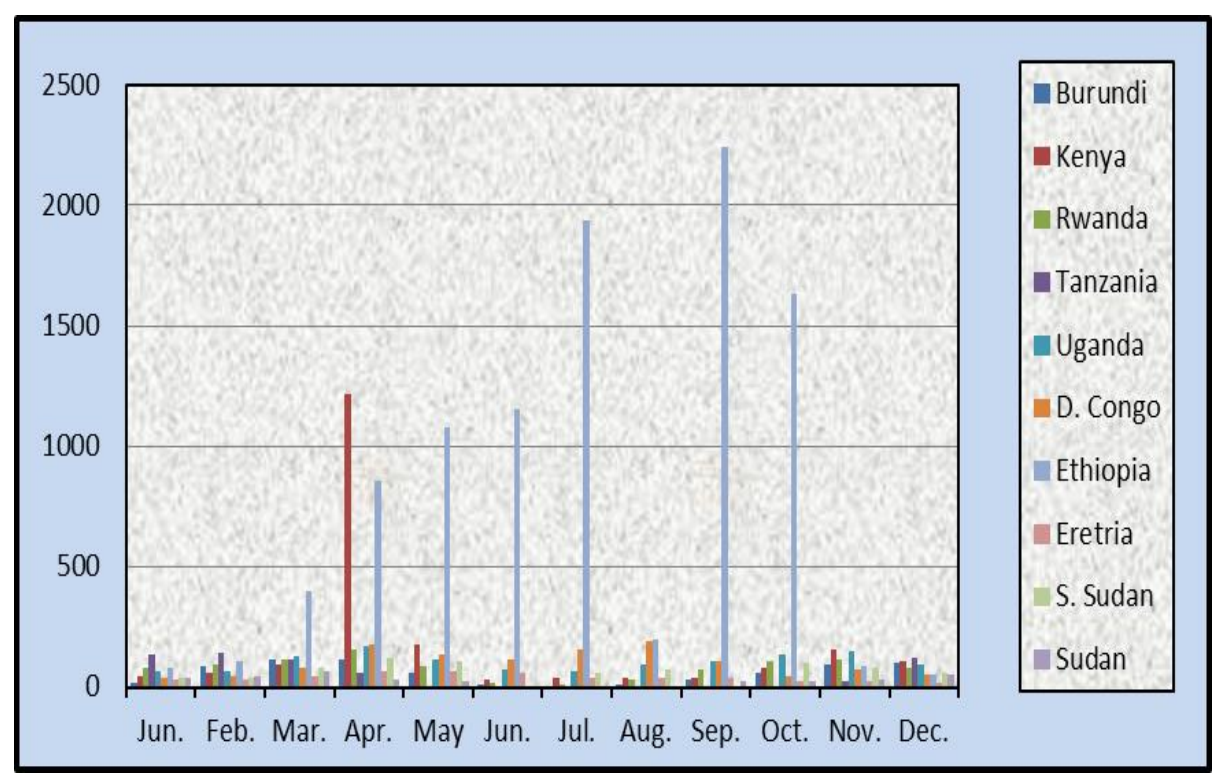

Figure (2)

The Nile basin countries has an optimal rainfall for the mosquitoes cycle range between so $\mathrm{mm}$ to $117 \mathrm{~mm}$ as it shown in table ( 3 ) especially in the countries like Kenya, D. Congo Ethiopia and Tanzania.

\section{2-2-1 Rainfall and Malaria}

Rainfall is consider the greatest of the climatic factors that affect malaria transmission in the population. Because of rainfall provides water for the breeding of mosquitoes. The average monthly rainfall was estimated at nearly $117.6 \mathrm{~mm}$. A one percent in rainfall increase preceding month reduced malaria incidence by about $2.1 \%$ 
increasing amount of rainfall may reduce malaria incidence because of the run-off water washes away most of the breeding sites of mosquitoes (Werns whern Dorfer, WH; 1989, p.923).

The increase in maximum and minimum temperature with rainfall attributed to change of weather seasons that make malaria incidence might reduce and mosquito might be increased so the malaria may increase.

The results revealed that malaria incidence is highest in month of January during the dry season and starts to reduce in the month of February and March, also it rise in the months of April and May during the rainy season. There is a great decline in malaria incidence in the months of August and September followed by an increase in October and November with a deeply decline in December.

\section{2-3 Distribution of the estimated malaria cases according to climate:}

Most of malaria transmission activate on the different seasons, as it shown in the table (4) and fig. (3) That indicate: 
Table (3) Distribution of the estimated cases on the four seasons in the basin Nile countries 2019:

\begin{tabular}{|c|c|c|c|c|c|c|c|c|c|c|}
\hline \multirow[t]{2}{*}{ Country } & \multicolumn{2}{|c|}{$\begin{array}{l}\text { Winter } \\
\text { month }\end{array}$} & \multicolumn{2}{|c|}{ Spring month } & \multicolumn{2}{|c|}{$\begin{array}{l}\text { Summer } \\
\text { month }\end{array}$} & \multicolumn{2}{|c|}{$\begin{array}{l}\text { Autumn } \\
\text { month }\end{array}$} & \multicolumn{2}{|l|}{\begin{tabular}{|l|} 
Total \\
\end{tabular}} \\
\hline & Cases & $\%$ & Cases & $\%$ & Cases & $\%$ & Cases & $\%$ & Cases & $\%$ \\
\hline Burundi & 1.2 & 11.6 & 1.8 & 6.3 & 1.3 & 12.8 & 1.4 & 5.7 & 4.5 & 6.3 \\
\hline Kenya & 0.1 & 1.0 & 1.3 & 5.2 & 0.2 & 1.8 & 1.4 & 5.7 & 3.0 & 4.2 \\
\hline Rwanda & 0.9 & 8.7 & 2.0 & 7.9 & 0.3 & 2.7 & 1.4 & 5.7 & 4.6 & 6.5 \\
\hline Tanzania & 0.9 & 8.7 & 2.5 & 9.9 & 0.6 & 5.5 & 2.4 & 9.9 & \begin{tabular}{|l|l|}
6.4 \\
\end{tabular} & 9.0 \\
\hline Ugenda & 1.2 & 11.6 & 4.4 & 17.47 & 1.5 & 13.6 & 4.5 & 18.4 & 111.6 & 16.3 \\
\hline D-Congo & 3.2 & 31.0 & 11.0 & 43.6 & 3.4 & 30.9 & 10.7 & 43.8 & 28.3 & 39.9 \\
\hline Ethiopia & 0.7 & 6.8 & 1.0 & 4.0 & 2.3 & 20.9 & 1.3 & 5.3 & 5.3 & 7.5 \\
\hline Eretria & 0.02 & 0.2 & 0.03 & 0.1 & 0.1 & 1.0 & 0.05 & 0.2 & \begin{tabular}{|l|}
0.2 \\
\end{tabular} & 0.3 \\
\hline S-Sudan & 1.0 & 9.7 & 1.2 & 5.2 & 1.3 & 11.8 & 1.2 & 4.9 & 4.8 & 6.8 \\
\hline Sudan & 1.1 & 10.7 & 0.1 & 0.4 & $\mathbf{0}$ & $\mathbf{0}$ & 0.1 & 0.4 & 2.3 & 3.2 \\
\hline Total & 10.32 & 100 & 25.23 & 100 & $\mathbf{1 1 . 9}$ & 100 & 24.45 & 100 & 71 & 100 \\
\hline
\end{tabular}

Source: World Health Organization (WHO) 2020.

Climate change profile, some of the basin Nile countries, tear fund: 3. www.tearfund.org 2019.

National government of Ethiopia, Eretria Sudan, Kenya, Burundi 2019. 


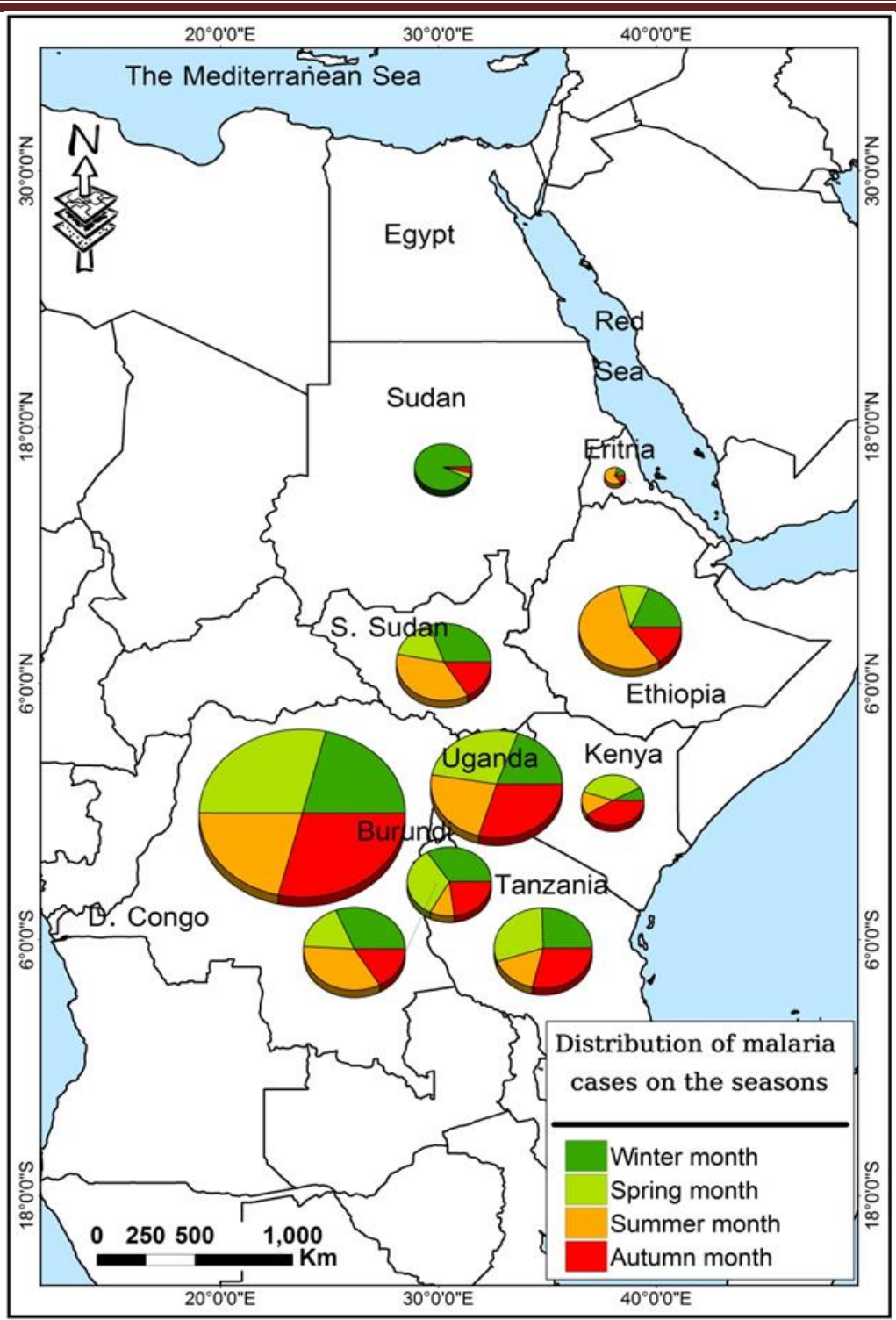

\section{Figure (3)}

- Most of the estimated case of malaria has appeared on the spring and autumn because these two seasons have two peak of rainfall that provide water for the breading 
of mosquitoes with an average months rainfall about $117,6 \mathrm{~min}$.

- We can notice this increase in Equatorial and tropical countries like D-Congo 87.4\% Uganda, 35.8\% Burundi $12 \%$, Rwanda $16.6 \%$ and Tanzania $19.8 \%$ of the estimated case in both two seasons, in the total estimated cases in the region

- Ethiopia has increase of estimated cases in summer $20.9 \%$ because of the monsoonal winds that below in summer till the first of autumn with a high temperature.

- Sudan regards an increase of the estimated cases in winter $(10.7 \%)$ because of the floods of Nile and may be cold in the winter

- D-Congo occupied the first rank in the estimated (39.9\%) cases because of equatorial climate that suits for malaria growth and transmission. Uganda also came is the second rank of estimated cases of malaria because it contains areas of altitude 1200 to $1600 \mathrm{~m}$, and the same is Ethiopia $7.3 \%$ with areas of altitude up $2000 \mathrm{~m}$ with temperature and humidity provide the perfect condition for malaria transmission.

\section{1-3 Highlands}

Uganda, Ethiopia, Kenya and Eretria have many areas of altitude up to 1200 to $2000 \mathrm{~m}$. The malaria endemic in these areas is so high. 
GIS-Based for Mapping Malaria Ris...

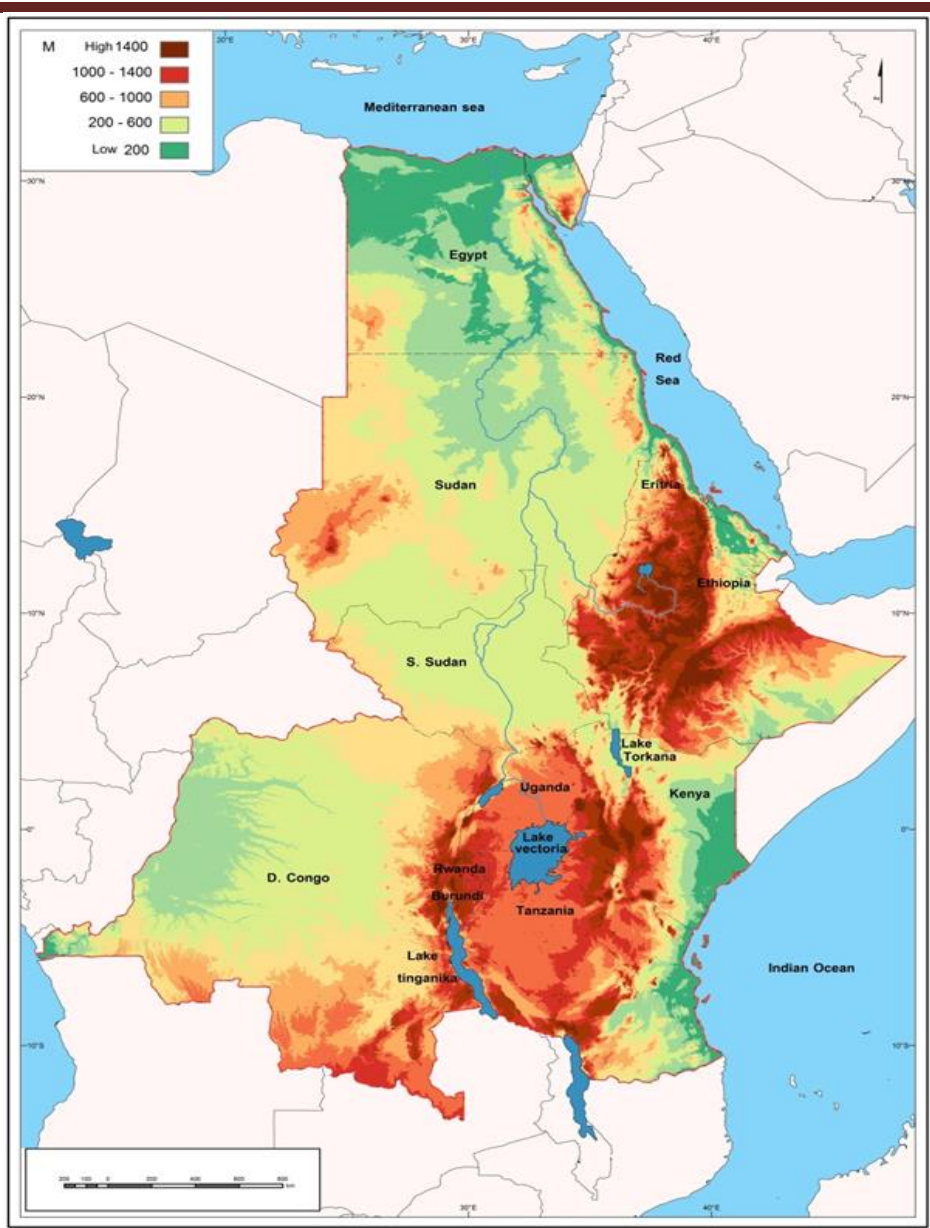

\section{Figure (3)}

The transmission of Malaria is active often after the rainy season (April-May and between (October- November). These areas have a temperature range between less than to 20 to $30 \mathrm{c}^{0}$, with a relative humidity more than $60 \%$ that provide optimal conditions for malaria growth and transmission. 
In the high lands of eastern basin Nile temperature plays effectively in the survival of parasites in the anopheles mosquito vector. These parasites distinguished with a short development cycle that lasts between 7 to 21 days. These parasites need an optimum temperature between 20-31 $\mathrm{c}^{0}$. It was known that temperature below $19 \mathrm{c}^{0}$ does not make the plasmodium falciparum species to grow and complete their cycle. Most of the east's countries of the Nile basin that have highlands with an average annual, temperature from $17^{0}$ to $36 \mathrm{c}^{0}$ that consider that optimum environment for the P. falciparum species in completing their cycle and spreading malaria in the population.

Moreover, malaria incidence is affected by some topographic factors such as altitude, and slope. In account, the negative relationship between the risk of malaria infection and altitude was well- identified. It was argued that malaria morbidity was significantly less prevalent in the highlands that experience relatively cold condition compared to lowlands (Maxwell, C.A, 2003, p36). Because of low temperature in high altitude limits parasite development and preventing the spread of malaria. Malaria risk is negatively connected with slope, where breeding sites of mosquitos are in gentle slope and Plaines

\section{1-4Floods and Malaria}

Climate change may affect health in different ways, such as flood may cause a health weakness. Floods are known to be the most divesting kind of natural disasters, representing for more than $40 \%$ of all natural disasters. 
Most floods happen in tropical region in the Nile basin (Samson, 2009, p34). Between 2000-2018, some countries in the Nile basin have experience many episodes, especially in 2007. Between natural disaster from 1980 to 2018 floods were occurred reported in some regions in the Nile basin nearly more than 67 floods. The health impacts of floods comprise drawing, hypothermia, injuries, animal bites and may cause of damages in the properties.

Health risks also are associated with evactiton of patients, loss of health workers and infected injury by, mosquitoes poising, poor mental health and poverty related diseases including malnutrition.

\section{1-4-1 The causes of floods:}

Floods are defined in occurrence when water overflows the natural, artificial confines of a stream and accumulation by drainage over low-lying areas (Weiwei, D, 2011, pp.1-3). The nature and consequences of floods vary according to the cause of the flood and the nature of the physical and human environment. The reasons of floods as the following:

\section{a- Precipitation}

Including rain can be the reason for the flash flooding and may cause foods.

b- Rising water levels 
That may happen suddenly especially as a result of planned damming of water drainage or the explosion of subterranean water to the surface.

c- Released of stored water

As a result of failure of retaining walls or structure by the displacement of stored water that may happen with landslides into the water.

\section{3-2 Failure of Natural drainage}

That a result of reducing abortion of water takes place when the natural landscapes is replaced with non-absorbent infrastructure, urban expansion or the replacement of wetlands. Also it may happens when the inadequate in draining systems in new construction or drainage systems which become blocked with trach (Amal Helmy, 2014, p51).

Health official ensured that malaria epidemics were phenomena common in the countries of the Nile basin that have floods. These countries authorities informed that high malaria incidence after floods as a result of increasing in mosquito breeding sites. Other studies have discovered a positive correlation between floods and the taking place of malaria in these countries.

Flood may cause malaria even in the arid and semiarid zones as a result of increasing Nile level during the season of rains and due to malaria may increase and expand. The countries government have to a careful planning and 
environmental management are required to avoid malaria in the future.

\section{The Nile and Malaria}

Nile is the longest river in the world, nearly $6.800 \mathrm{KM}$ and its basin equal $2.9 \times 10^{6} \mathrm{~km}$ It has a various sources such as two lakes Victoria and Tanah with other resources from neighbor like Congo and Logone-chari. In general, the Nile offers a pathway for African species to extend from the Tropics climate to Mediterranean climate. The Main Nile receives water from the sources of Ethiopian Highlands and the Equatorial plateau. From Ethiopia two tributaries connect with Nile, The first is Blue Nile and second is Atbara.

The table (4) show the fresh water resources of the Nile

\begin{tabular}{|c|c|c|c|c|c|}
\hline Country & $\begin{array}{l}\text { Average } \\
\text { annual } \\
\text { Precipitation } \\
(\mathbf{m m})\end{array}$ & $\begin{array}{l}\text { Nile river } \\
\text { inflow } \\
\left(\mathrm{mm}^{3} / \text { year }\right)\end{array}$ & $\begin{array}{l}\text { Outflow } \\
\text { (mm³/year) }\end{array}$ & $\begin{array}{l}\text { Confirmed } \\
\text { cases } \\
\text { "million" }\end{array}$ & $\%$ \\
\hline Burndi & 1110 & 100 & 1500 & 4.3 & 7 \\
\hline D. Congo & 1245 & 500 & 1500 & 21.9 & 35.3 \\
\hline Rwanda & 1105 & 1500 & 7000 & 0.639 & 1 \\
\hline Tanzania & 1015 & 7000 & 10,700 & 12.9 & 20.9 \\
\hline Kenya & 1260 & 500 & 8400 & 6100 & 21.4 \\
\hline Uganda & 1140 & 28700 & 37000 & 2.9 & 1.6 \\
\hline Eriteria & 520 & 100 & 2200 & 0.096 & 0.3 \\
\hline Ethiopia & 1125 & 1000 & 80100 & -1 & 1.1 \\
\hline Sudan & 500 & 117100 & 55500 & -7 & - \\
\hline Egypt & 15 & 55500 & 1000 & - & - \\
\hline total & 9035 & 2229000 & 303400 & 61636 & 100 \\
\hline
\end{tabular}

Source: FAO, Nile Basin Dataset. Database prepared by FAO land and water Unit, Rome, Italy, 2016. 


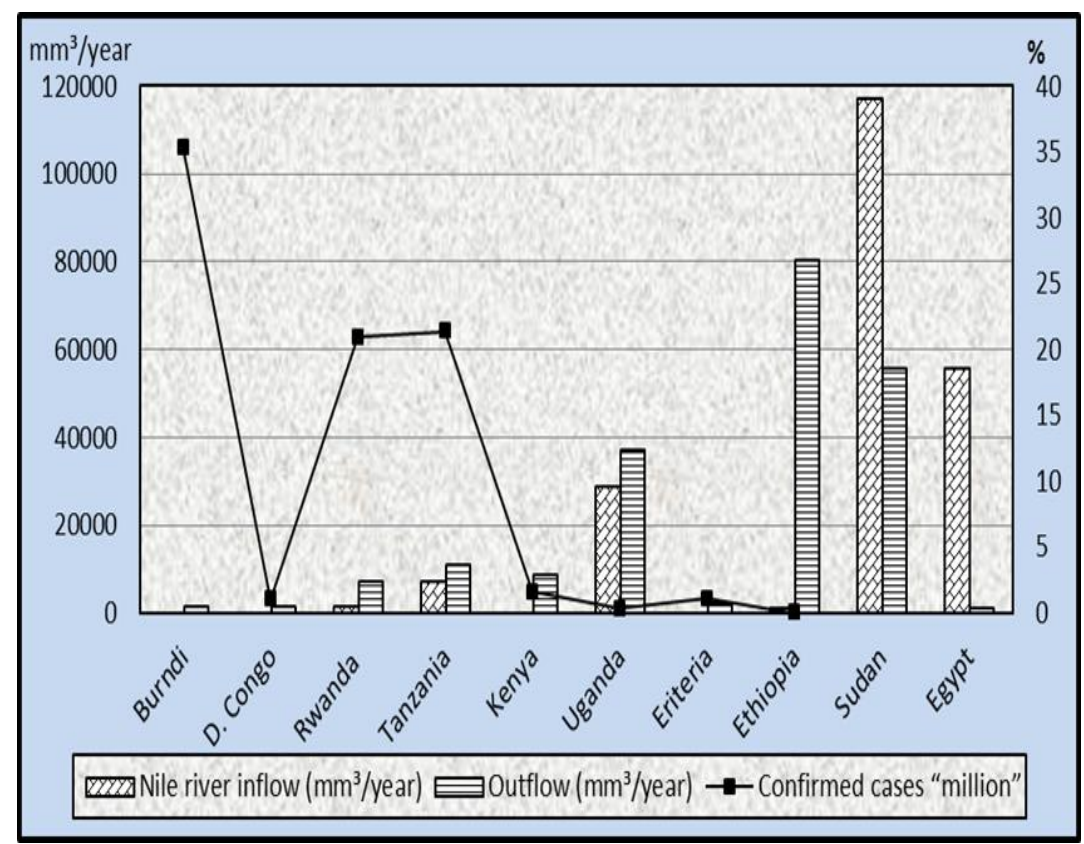

Figure (4)

The equatorial regions include western Kenya, Uganda, Rwanda, Burundi, besides the source of the central. Republic of Congo, Central African Republic and the Demo crating Republic of the Congo. The Nile basin also covers Egypt and Sudan. The basin also covers about $1 / 3$ of Ethiopia, the whole of Uganda and a great parts of Kenya, Tanzania, Congo, Rwanda and Burundi. The Nile divided into a number of Sub-Basin as the following:

1. The White or equatorial Nile that has a surface area of ca $3.8 \times 10^{5} \mathrm{KM}^{2}$.

And as known the vastest river. 
2. Lake Victoria contain a surface area of $7 \times 10^{4} \mathrm{KM}^{2}$ and occupy the second in size to the Caspian Lake in west Asia.

3. Lakes Albert and Edward that obtained their water from Ruwenzori and Virunga highlands.

4. The Nile River has an annual flow of freshwater of nearly $229000 \mathrm{~mm}^{3} /$ year and the amount not including the soil water that consumed by natural vegetation (FAO, 2016) and outflow approximately $3034000 \mathrm{~mm}^{3} /$ year.

5. Because of the height of average annual precipitation $(\mathrm{mm})$ of the Nile and the increase in inflow and outflow of water that may the ideal environment for growth mosquitoes that transmit Malaria and it was main that he confirmed cases have reached to 61.6 million.

6. Congo, Kenya and Tanzania occupied the ranks one the first to third Because of inflow and out flow of the Nile.

\section{II- The Social Environmental.}

\section{Deforestation:}

Forest resources that has generated severe environmental, ecological and public health problems including in vector-bane diseases such as malaria. Forest are among the world's most important biomes in terms of the area of land surface they cover nearly $30 \%$ of all land-over, 3.8 million hectares (FAO, 2003). 
The forest provide to who depend on it (1billion people) all over the world in their living, and 60 million indigenous people are nearly wholly dependent on forest. While 350 million people living with dense forests depend on them to a light degree for subsistence and income in developing countries, a gro-foresty farming scheme support 1.2 billion people and help, sustain agricultural productivity. Forest industry provide employment for 60 million people in the countries of the Nile basin.

Deforestation alters all elements of local ecosystems like microclimate, soil, and aquatic conditions, and the ecology of local flora and fauna, including disease vectors, all the forest vector spices, which transmit disease to humans, mosquitoes, are the most sensitive to environmental changes because of deforestation. Their survival, density, and distribution are dramatically influenced by small changes in environmental condition like temperature, humidity, and the availability of suitable breeding sites (Grillet ME, 2000, 233)

Changes in mosquito ecology and human behavior pattern in forested regions affect it the transmission of mosquitoes borne disease live malaria. Each incident of deforestation and land transformation has a different influence on the spreading, incidence and distribution of malaria.

Table (5) the area of forest, number of population who live in the forest, population at risk and estimated cases of Malaria. 
GIS-Based for Mapping Malaria Ris...

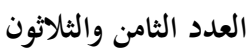

\begin{tabular}{|l|l|l|l|l|l|l|l|l|l|}
\hline Country & $\begin{array}{l}\text { Area } \\
\text { feddan } \\
\text { /thousand }\end{array}$ & $\begin{array}{l}\text { \% of } \\
\text { the } \\
\text { country } \\
\text { space }\end{array}$ & $\begin{array}{l}\text { No. of } \\
\text { people } \\
\text { who live } \\
\text { in forest } \\
\text { (million) }\end{array}$ & $\begin{array}{l}\text { \% of the } \\
\text { population }\end{array}$ & $\begin{array}{l}\text { Population } \\
\text { at risk } \\
\text { million }\end{array}$ & & & $\begin{array}{l}\text { Estimated } \\
\text { cases } \\
\text { million \% }\end{array}$ & $\begin{array}{l}\text { \% of } \\
\text { population }\end{array}$ \\
\hline Burundi & $\mathbf{0 . 1}$ & - & 6 & 1,01 & 9.2 & 1.016 & 100 & 1.016 & 100 \\
\hline D.Congo & 67.9 & 18.1 & 52.2 & 42.6 & 49 & 42 & 98.6 & 19 & 44.6 \\
\hline Eriteria & 0.7 & 0.2 & 2.2 & 0.3 & 8.6 & .170 & 56.7 & $\mathbf{0 . 1 0 0}$ & 33.3 \\
\hline Rwanda & 1.7 & 0.5 & 12.2 & 0.8 & 6.3 & .6 & 75 & 0.250 & 31.3 \\
\hline Uganda & 5.2 & 1.4 & 20.8 & 12 & 27.1 & 8 & 66.7 & 5.4 & 26 \\
\hline Tanzania & 79.2 & 21.1 & 37.2 & 15,5 & 26.7 & 14.3 & 92.3 & 6.7 & 43.2 \\
\hline Ethiopia & 1.2 & 0.3 & 3.6 & 7 & 6.3 & 6 & 85.7 & 2.1 & 30 \\
\hline Kenya & 0.3 & 0.1 & 2.1 & 3.7 & 5.7 & 2.1 & 56.8 & 1.7 & 45.9 \\
\hline S. Sudan & 42.4 & 11.3 & 27.2 & 3 & 27 & 3 & 100 & 1.7 & 56.7 \\
\hline Sudan & 176.2 & 47 & 27.6 & 12.1 & 8.3 & 11.2 & 92.6 & 1.4 & 11.6 \\
\hline Total & 374.9 & 100 & - & 98.1 & 26.1 & 88.4 & 90.4 & 40.366 & 41.2 \\
\hline
\end{tabular}

Source: 1- the area of land space and number of population from the countries of the Nile basin.

2-World Health Organization, 2010.

3-WHO,2019: communicable disease epidemiological profile for Horn of Africa,2019 Geneva, Switzerland.

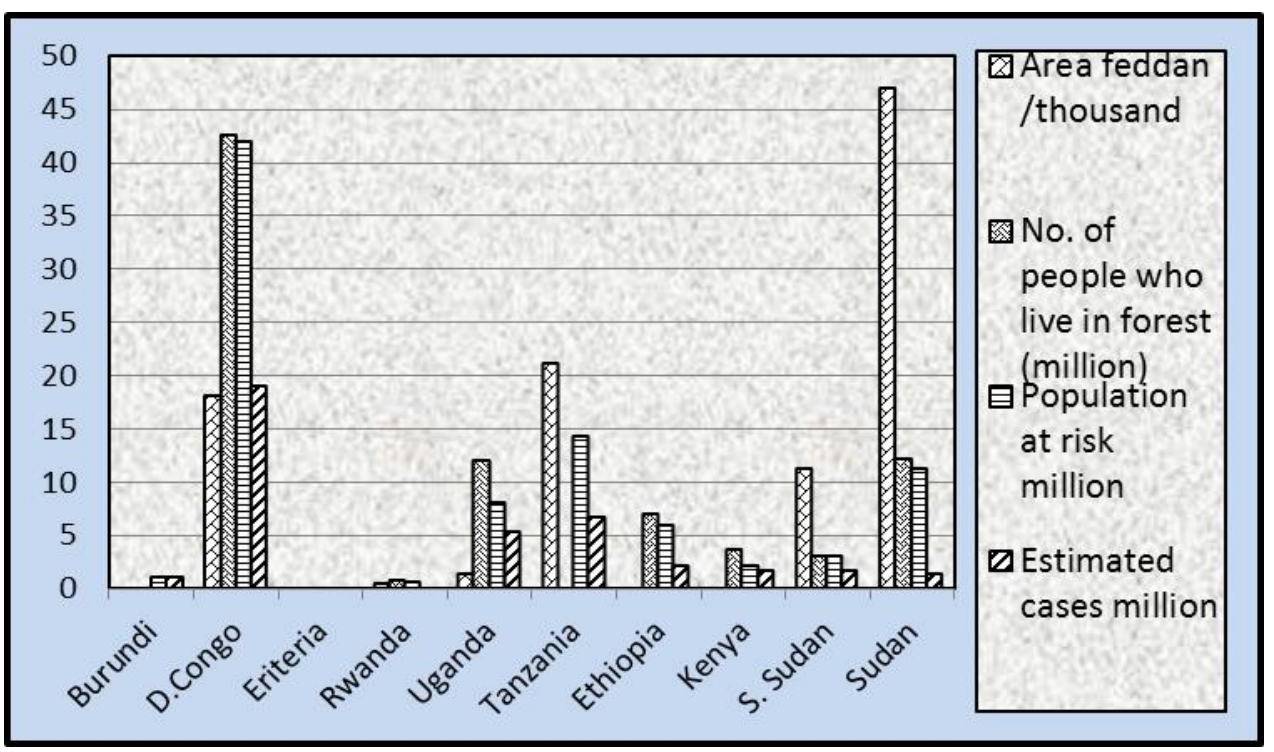

Figure () 
Road building, trees felling, reduced shade and increased pooling of water that helped to promote breeding more speedy of development of mosquito larva (Afane YA, 2005, p80).

The malarious region in the forest in the Nile basin countries vary from 1.9 to 5.2 million $\mathrm{Km}^{2}$. The forest biodiversity and the natural functioning of health forest ecosystems. Take part to human health. Forest spices take part to balanced diets, and are a major component of traditional health care systems. The forests provide the primary healthcare for nearly two-third of the global population (Fransworth NR. 1994, pp 44-46). The medical need of nearly one billion people on drugs derived from forest plants that used in traditional medicine. Deforestation in malarias are range from 36.000 to $69000 \mathrm{~km}^{2} /$ year (Guerra CA, 2006 p100), more than $80 \%$ of earth's natural forests have been destroyed 40 million hectares per year). Up to $90 \%$ of African forests have disappeared since 1900. Most of forest of the Nile basin countries deforestation caused by slash and burn agriculture. Malaria is a major killer near forested areas in Africa because of deforestation for farming has allowed population to enter areas that malaria live, also uses water made an increase in mosquito breeding sites.

From the table (1) we can follow:

- The forests area in the Nile basin cover 374.9 thousand feddan, Sudan and Tanzania take the first and second 
rank with a percentage $47 \%$ and $21.1 \%$ of the Nile basin area.

- There are 98 million people are living in forests and these people rely on the forest in their living, and they represent 26.1 of the population in these countries.

- There are more than 88.4 million are at risk of malaria who represent nearly $90.2 \%$ from the people who live in forests because of the increasing in mosquitoes breeding sites and speed of development of mosquito larva.

- The estimated cases represent 40.4 million people and represent $41.2 \%$ of the population who live in the forest areas.

\section{Dams}

More than 2000 big dams have been established and over 210 are under establishment in sub Saharan Africa (SSA) in the countries of the Nile basin, there are 86 dam have been constructed. these dam aim to exist food security, increasing hydropower generation, managing variability and promoting economic growth (Zarif C. 2015, 77) Although the benefits of these dams but it is discovered, that these dams may caues increasing malaria such as the Kambara Dam in Kenya, the Koka reservoir in central Ethiopia, and the Gilgl Giba Dam in south west Ethiopia.it is Estimated that more than 9 million people were at risk and that 85000 million a year where connected with large dams in the Nile 
basin countries; we must understand that dams may cause malaria with other impacts by ecological, entomological and climatic factors.

It is found that dams may increasing malaria in areas of unstable (seasonal) transmission but had a much lower effect in area of stable transmission (kibret S, 2015, p.73). Dam building in the region of Nile basin will continue and accelerate the programed for infrastructure development in Africa (PIDA) calls for and expansion of hydroelectric power generating capacity by more $54.000 \mathrm{MW}$ and the water recent years that helped to satisfy its growing energy demad, and the country is currently building an additional eight large dams, including the huge grand renaissance dams federal democratic republic of Ethiopia, 2015 ).

Table (5) Number of dams in the Nile basin countries in 2109

\begin{tabular}{|l|l|l|l|}
\hline Country & $\begin{array}{l}\text { Dams } \\
\text { No. }\end{array}$ & $\begin{array}{l}\text { Estimated malaria } \\
\text { million }\end{array}$ & $\begin{array}{l}\text { Confirmed } \\
\text { malaria Million }\end{array}$ \\
\hline Sudan & 12 & 0.3 & 0.2 \\
\hline Ethiopia & 19 & 1.1 & 0.6 \\
\hline Uganda & 10 & 1.2 & 1.0 \\
\hline D-Congo & 13 & 1.8 & 1.2 \\
\hline Burundi & 2 & 0.2 & 0.1 \\
\hline
\end{tabular}


GIS-Based for Mapping Malaria Ris...

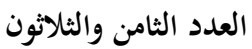

\begin{tabular}{|l|l|l|l|}
\hline Rwanda & 3 & 1.2 & 0.5 \\
\hline South Sudan & 4 & 1.1 & 0.6 \\
\hline Tanzania & 5 & 1.7 & 1.2 \\
\hline Kenya & 3 & 0.9 & 0.7 \\
\hline Egypt & 10 & 0 & 0 \\
\hline Ariteria & 13 & 0 & 0 \\
\hline Total & 86 & 9.5 & 6.1 \\
\hline
\end{tabular}

Source: 1-WHO, World Health Organization, world malaria report 2020 .

2-National government, at Ethiopia, Eriteria, South Sudan, D-Congo and Tanzania, 2019.

3-The program of infrastructure development in Africa, 2014. 


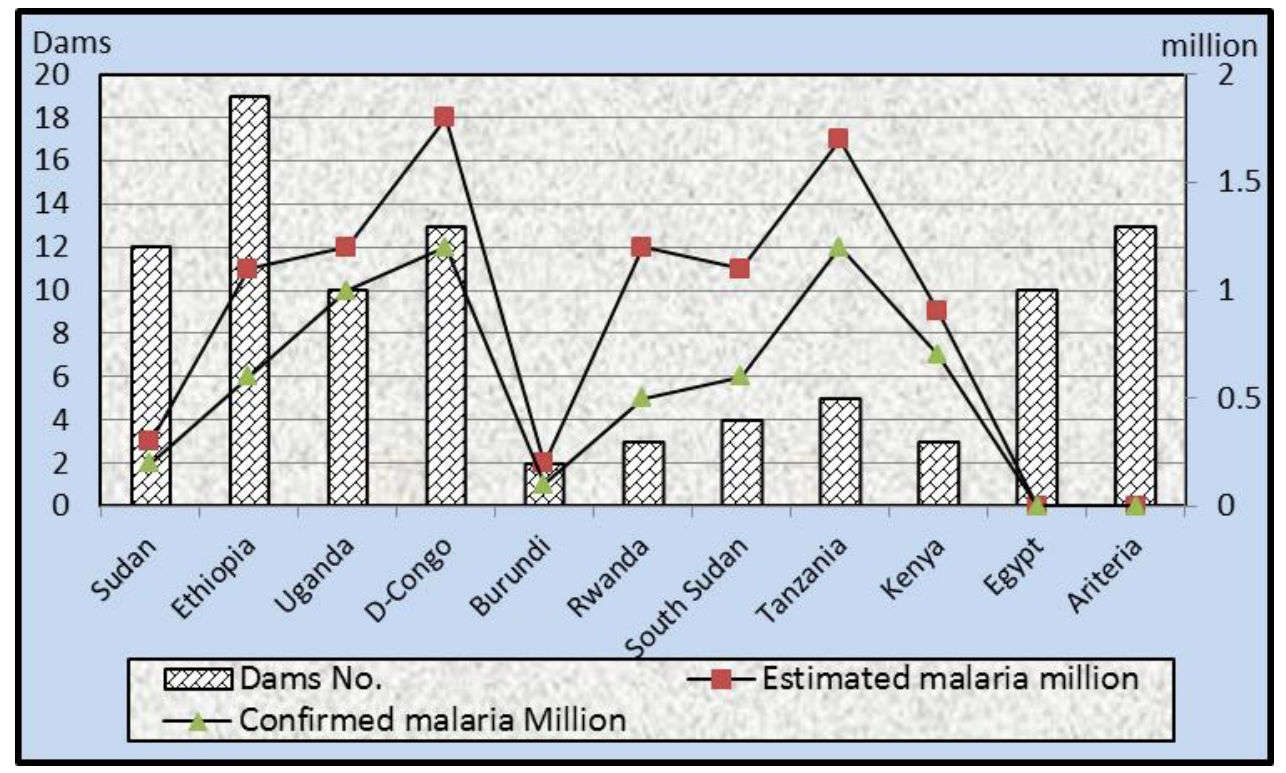

Figure ()

- The increasing of malaria around dams as a result the water storage provides potential mosquito a breeding habitats and climate determines the development of mosquitoes and malaria parasites plasmodium falciparum is the most prevalent and most total malaria parasite in the region around dam. Anopheles Gambia and anopheles Faustus spread in wet and humid areas, while anopheles Arabians is spread in drier climates (Solomon Kibret, 2010, p. 22).

From the table (5) we indicate the following:

- The Nile basin countries have built 86 dams for generating hydropower and for saving water for Irrigation, Ethiopia, D. Congo , Sudan , Uganda and 
Egypt occupied the advanced ranks in building dams with $74,4 \%$ of total dam.

- The region around the dams in the basin Nile counties contain $9,5 \%$ million of estimated cases of malaria. Nearly 6,1 million of confirmed malaria in these region because the water storage that help mosquitoes in breeding (WHO,2018)

\section{Agricultural}

- In the eastern part of Africa especially Uganda, Kenya, Tanzania, and Ethiopia where the Malaria is more prevalent during season of peak agricultural activities, the disease of malaria not only excludes the sick ones from daily agricultural activities but also the healthy ones that have to concern of their sick family and relatives. According to the governmental statistics, $80 \%$ and more of these countries population is employed in agriculture sector.

- Agriculture is the most important economic source for the Nile basin countries, and these countries still depend on natural climatic conditions of rainfall and temperature. Millions of the cultivating workers are burden of malaria that affect in their health and their incomes, and in food security at household level. It is estimated that the agriculture workers suffering from malaria can be incapacitated for 5-20 day. The lock of manpower during the season of agricultural activities decrease productivity, so they suffer from decreasing of 
their income and food insecurity (Goodman CA, 1999, p378-385).

- The burden people of malaria may spend up to $25 \%$ of its income on malaria prevention and treatment. It is estimated that $40 \%$ of health costs in the Nile basin countries spent of on the treatment of malaria.

From the (6) its noticeable the following:

- The cultivated area cover $43.7 \%$ of the Nile basin countries because it represent the economic source for their National income and supply them with food security.

- There are $66.1 \%$ of the total population are working in agriculture, nearly $91.3 \%$ of Burundi are cultivated workers, and Ethiopia are working in cultivation.

- They are suffering from malaria because their working in agriculture are dealing with water that may contain the breeding sites of mosquitoes and many of them exposed to mosquitoes injects that cause the Malaria.

- Nearly 45.7 of the estimated Malaria are in the cultivated workers and the percentage very high in Burundi, Uganda, Rwanda and Ethiopia with 56.53 .52 and $51 \%$ of the total Number of cultivated worker.

Table (6) Distribution of the cultivated lands and estimated Malaria in 2019

\begin{tabular}{|l|l|l|l|}
\hline & Cultivated & Cultivated & Estimated \\
\hline
\end{tabular}


GIS-Based for Mapping Malaria Ris...

العدد الثامن والثلاثون

\begin{tabular}{|l|l|l|l|}
\hline \hline & $\begin{array}{l}\text { land the } \\
\text { country area } \\
\%\end{array}$ & worker \% & $\begin{array}{l}\text { Malaria in } \\
\text { worker \% }\end{array}$ \\
\hline Burundy & 79.1 & 91.3 & 56 \\
\hline DR. Congo & 11.6 & 65.3 & 42 \\
\hline Eriteria & 75.2 & 57.1 & 43 \\
\hline Ethiopia & 36.3 & 70.8 & 51 \\
\hline Kenya & 48.5 & 62.3 & 46 \\
\hline Rwanda & 73.4 & 735.2 & 52 \\
\hline Sudan & 28.7 & 33 & 24 \\
\hline S-Sudan & - & - & \\
\hline Tanzania & 44.7 & 67.3 & 44 \\
\hline Uganda & 71.4 & 72.4 & 53 \\
\hline Average & 49 & 66.1 & 45.7 \\
\hline
\end{tabular}

Source:

http://Data,albankadawilli.Org/indector/sl.AGR.EMPL.FE.Z S?view.cha.com - prepared by researcher depending of World Bank Data, 2014.

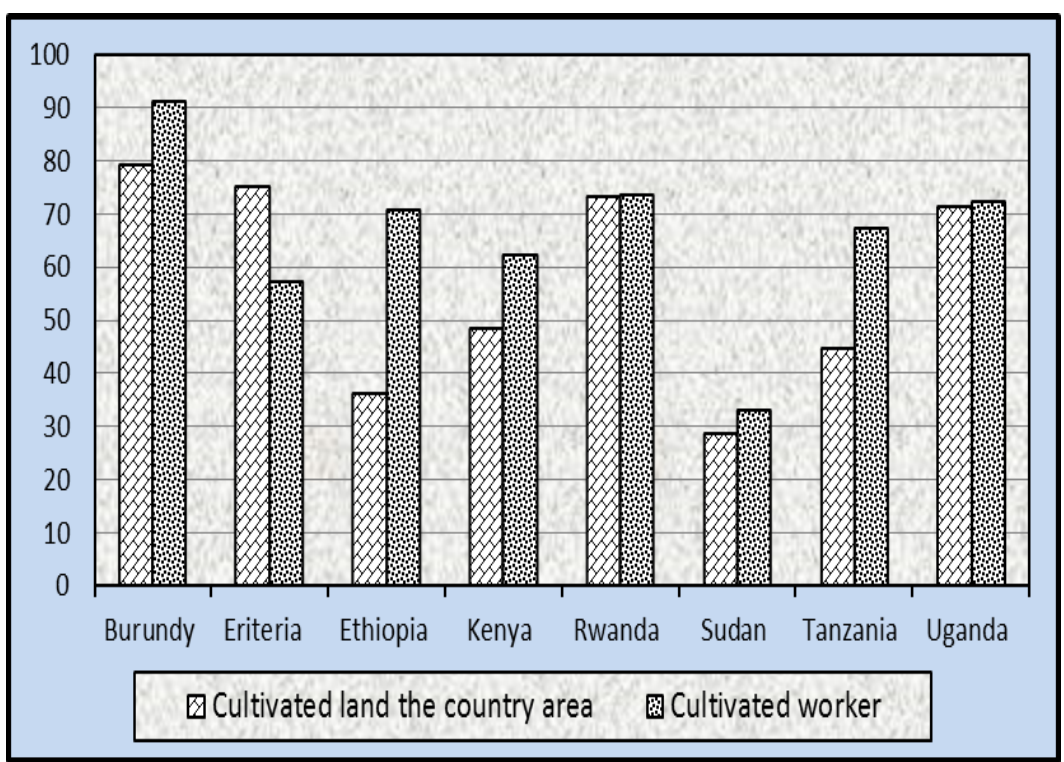




\section{Figure (9)}

\section{Urbanization:}

The rapid increase in the world's unban population has a great implication for the transmission and epidemiology of malaria and other vector diseases. This situation may be true in the Nile basin countries that distinguished rapidly urbanizing region in Africa contentment, with the highest rates of plasmodium falciparum. Transmission although some cases are happened from rural areas, malaria transmission in urban is a significant problem.

Many explanations for why urban areas seems to have lower malaria transmission rates compared with rural areas. The first explanation is the pollution affects larval habitats, the life cycle of mosquitoes and vactorial ability. The second explanation include mosquito avoidence by urban population, such as screen, doors, insecticides and bed nets. Higher human population densities may reduce biting rates, (Vincent Robert, 2003, p.169) like the cities of Khartoum, Addis Ababa, Nairobi and Aum Dorman.

The post-World war II era has been characterized by a rapid increase in the world's population, especially in the Nile basin tropical areas. In 2000 their population was estimated to be 320 million, these regions were remained rural until now. In 1900 more than $10 \%$ of the Nile basin population in an urban area, and by 1950 , only $15 \%$ lived in urban area. Today nearly a half of population, and the proportion is expected to increase over the next 25 years. 
Although rapid urban growth is a relatively recent phenomenon in these countries. The cities of almost 500.000 population are grown faster, than any other area of the world (World Bank, 2001). This urbanization rate at $2 \%$ for the 35 year, a doubling of the urban population every 37 years. Most of the cities suffer from pollution, poor housing, and lack of sanitation, unprotected water reservoirs, weak services, low productivity and bad economy. The life in the rural cities has many problem such as increasing density of households, difference in house material, very bad economic, a difficulty in public transport.

There are three anopheles of mosquitoes that Transmitted to population and they anopheles Gambia, anopheles arabiersis is and anopheles funfests that spread in urban cities by their ten anopheles spices malaria transmission are concentrated in rural cities (Elissa N, 1999, p195).

Urban environments may influence malaria transmission in several ways. By replacing vegetation with asphalt and concrete, urbanization may reduce the number of larval habitats. In many urban areas, vegetation remains, couple with urban farming, after provides ample aquatic habitats for mosquito's physical deterioration, new construction activities such as building construction and irrigation schemes, and an increases in human activity may increase opportunities for mosquitoes through an increase in the number of artificial water reservoirs. In these areas, 
water pipes are broken to produce water for sale and consumption.

The anopheles Gambia complex is less effective in urban areas because there are fewer breeding sites, people who live in urban areas are on average 10 times less probably to receive an infective bite than their rural areas. (Hay, S.I, 2002, p 417).

\section{Population movement and malaria}

- The movement of population are an old phenomenon: as a result from wars and natural disaster since ancient times Also a very great numerous of conflicts in the African regions made millions of people to leave their home lands and seek refuge to another areas or in neighboring countries.

- The natural disasters like floods or droughts cause to food shortages. In recent years many forced people movements have happened in Africa and Nile basin region where malaria constitutes in the public health threat. World Health Organization put list of environmental disruption for cultivation, sociopolitical unrest, and migration as causes of the malaria problems (World Health Organization, 2015a) Also it has estimated that the third of malaria death in Africa and Nile basin region happen in some countries that effected by complex emergencies . General malaria happens in more than 80 countries worldwide and $35 \%$ of the world population live where there is risk of malaria such as ten countries of the Nile 
basin and 35 countries in Africa (world Health Organization 2020a). The dangerous of malaria represent in increasing morbidity, loss of productivity. Anemia and malnutrition in Africa and Nile basin region. Public health responses to the population movements due to natural disaster. Many factors like the intensity of malaria transmission, the level of population immunity, the biology of the kind of parasite and vector, and the location's ecology can all affect the shape of an integrated in the efforts of malaria control because of their many technological solutions to the uncertainties that represented by these variable, many of them and not cheap and complex. Malaria is a great major cause of illness and death among displaced population. Human movement has had a tremendous effect on the global malaria situation.

- Among 40 countries with a risk of malaria transmission in the Africa and the Nile basin countries have shown the human mobility as the greatest cause of the transmission of malaria.

- Migration has been connected with the spread of drug resistant malaria in the Nile basin region. For example in Kenya, seasonal movement of the workers from lowland district to highland tea plantation has been connected with yearly epidemics (Snow R.W., 1998, p. 52).

- Seasonal movements of migrant farm workers from Uganda to Sudan has been connected without breaks of 
transmission of malaria. Even movements of Malaria endemic, areas may cause disastrous consequences.

- A big numbers of population from urban areas for economic reasons such as Ethiopia and Sudan or to organized setting, like as planned refugee camps such as south Sudan, Ethiopia and Kenya most of the Nile basin has a rapid growing population who can strain the capacity of rural districts and cause to population basement (martens and Hall, 2000,p) Also searching for new cultivated are make people in the Nile basin to de for estate. In the bas in Nile countries Malaria was the primary cause of morbidity and mortality among south Sudanese Ethiopian refugee and malaria in these countries a counted 1 to $5 \%$ of all deaths especially the Ethiopian refugees in eastern Sudan (centers for disease control, 1992). In 1994 Rwandan refugee crisis in eastern Zaire (D- Republic of Congo) and malaria caused to death to many of Rwandan till 1996 and the same Ethiopian.

- An organized relocation such settlement of nomadic people such as in Sudan, Eritrea, and Tanzania may helped them to prevent malaria. The greater concentrations of population can create highly focal areas of people travel from none demit districts into malaria areas to obtain in forming and mining and then become sick of malaria.

- Irrigation projects or hydroelectric water production have been in Uganda, Ethiopia, Sudan, Kenya and Burndy and 
these projects facilitate mosquito breeding and malaria transmission.

- Most of the countries of the Nile basin in the urban cities this rapid urbanization with poor housing of temporary establishment, and the lack of health care, sanitation and may the shortage of proper drainage leading to the growth of mosquito breeding and increasing exposure to reactors as a result of poor housing after the heavy monsoon rainfall in Ethiopia may causes of the increase in mosquito breeding sites. The same happen after heavy rains or flooding in D. Conge, since 30 years, food shortages caused by drought and caused wars in Rwanda, Burundi and Uganda that have a frequent cause of the population basements and the population exposed most of them to malaria and placing them at high risk of malaria (Anonymous, 1999).

From table (7) we can indicate the following :

- The land Malarious in million $\left(\mathrm{km}^{2}\right)$ has been decreased from 58.6 to 38.7 million $\left(\mathrm{km}^{2}\right)$ with a decrease rate equal $43 \%$ as a result of $\mathrm{WHO}$ effort in struggling the disease.

- Also many countries has got rid of Malaria as the number decreased from 130 countries to 89 countries with a decrease rate equal $31.5 \%$.

- Nile basin Malarious in $\left(\mathrm{km}^{2}\right)$ regarded an increase from 4 million $\left(\mathrm{km}^{2}\right)$ to 5.2 million $\left(\mathrm{km}^{2}\right)$ with an increase rate 
$30 \%$ because of the poverty for all countries in the region and their government can't able to fight the disease.

\section{Human population at risk of malaria through history}

The human population has grown during 20 century from nearly 2.2 billion to 7.6 billion as it is shown in table (7). These demographics have a great important implication for the rate of the human population exposed to malaria risk through history the percentage of the world population at risk of malaria has decreased from $68.4 \%$ at 1945 to $46.2 \%$ in 1992 . The number increased to 48.3 in 2002 and it increased to 52.5 in 2019 due the population growth with a stable in geographical distribution. The change in population exposed to different rates of emdemicty from 1945 to 2019. The Nile basin exposed at risk of malaria has regarded an increase around 27.7 to $30 \%$ between 1945-2019 in comparison with Africa.

That has not increased from $18.1 \%$ to $23.7 \%$ between their long pried as a result of the difficulty facing of infection with p.falaparum and p. vivax (Medis,.k., 2001,p.65).

Table (7) World population at Malaria's risk from 1990 to 2014 in

\begin{tabular}{|c|c|c|c|c|c|c|c|c|c|c|c|c|c|}
\hline & & & & & & \multicolumn{8}{|c|}{ comparison with the Nile basin } \\
\hline Year & $\begin{array}{r}\text { World } \\
\text { populati } \\
\text { on }\end{array}$ & $\begin{array}{r}\text { Land } \\
\text { Malarias } \\
\mathrm{Km}^{2} \\
\text { (million) }\end{array}$ & $\begin{array}{r}\text { Countri } \\
\text { es at } \\
\text { risk } \\
\text { world }\end{array}$ & $\begin{array}{r}\text { World } \\
\text { population } \\
\text { in the } \\
\text { exposed } \\
\text { (million) }\end{array}$ & $\%$ & $\begin{array}{r}\text { African } \\
\text { exposed } \\
\text { (million) }\end{array}$ & $\begin{array}{r}\% \\
\text { World }\end{array}$ & $\begin{array}{r}\text { Nile basin } \\
\text { exposed } \\
\text { (million) }\end{array}$ & $\begin{array}{r}\% \\
\text { Afric } \\
a\end{array}$ & $\begin{array}{r}\text { African } \\
\text { land area } \\
\text { Malaria } \\
\mathrm{Km}^{2}\end{array}$ & $\%$ & $\begin{array}{r}\text { Nile basin } \\
\text { Malaria } \\
\mathrm{Km}\end{array}$ & African \\
\hline 1945 & 2192 & 58.6 & 130 & 1635.8 & 68.4 & 296 & 18.1 & 82 & 27.7 & 20 & 34.1 & 4 & 20 \\
\hline 1965 & 3363 & 53.5 & 103 & 1424.3 & 57.1 & 381 & 19.8 & 118 & 30.9 & 21.2 & 39.6 & 4.4 & 20.7 \\
\hline 1992 & 5419 & 43.7 & 88 & 2505.7 & 46.2 & 508.1 & 20.3 & 163 & 32.1 & 22.1 & 50.6 & 5 & 22.6 \\
\hline 2002 & 6204.1 & 39.8 & 87 & 2446.4 & 48.3 & 565 & 18.9 & 192 & 33.9 & 16.2 & 35.7 & 5.1 & 26.6 \\
\hline
\end{tabular}


GIS-Based for Mapping Malaria Ris...

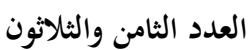

\begin{tabular}{|r|r|r|r|r|r|r|r|r|r|r|r|r|r|}
\hline 2010 & 6807.1 & 39.8 & 88 & 3410.9 & 6.1 & 742 & 21.8 & 248.3 & 33.5 & 19.7 & 49.5 & 5.3 & 26.9 \\
\hline 2019 & 7670 & 38.7 & 89 & 4028.1 & 52.2 & 593.4 & 23.7 & 290 & 30 & 19.9 & 51.4 & 5.2 & 26.1 \\
& & & & & & & & & & & & & \\
\hline
\end{tabular}

Source: 1- the area land Malaria were collected from using maps of all Malaria risk distribution through history.

2- Environment system research, institute, INC, red lands, California, USA, various years.

3- World population database (http://esa.un.org/unpp/between1945to2019.

4- (WHO) World Health Organization, various years.

\section{Controlling Malaria from 1945-2019}

- During the last century a great improvements in the control of discovering diseases, as a result of environment improving, also in social condition such as housing and trying to change the land use (especially agriculture habitats) taking part to the global reduction in the spread of Malaria. These gains from Malaria control were connected with economic and social development. To fight Malaria the world followed several distinct phases.

- The first was the great concentration on environmental control of mosquito's sites, through many studies that concerned of anopheles mosquitoes in the live history of Malaria (Shousha A.T., 1948, p.55).

- The discovery of the residual insecticide such as (DDT) in the 1940s helped in covering, a large-scale or wide 
area of Malaria. Since 1963, the restriction of the world distribution of Malaria has resulted from the progress of national effort in developing incomes of African countries and other countries. In 1998, the world discovered the roll back Malaria movement as advocacy vehicle for international Malaria control that helped to reduce the world Malaria burden of risk morbidity and mortality especial in 2010. To understand this bold ambition roll back Malaria has four aims to complete $60 \%$ coverage of children and pregnant woman with insecticide tread Nets, (ITN), to have $60 \%$ of Malaria cases it need effective treatment with $24 \mathrm{~h}$ of the beginning of symptoms.

\section{Development in the Malaria}

African continent occupy the first rank in the world in estimating Malaria cases in the world with 215 million cases represent $93.3 \%$ from the estimated cases in the world and death cases equal $93.9 \%$ as it shown in the table (8) indicate the following:

With an estimated 71 Malaria and 126.5 thousand death in this basin Nile region accounted for about $33.7 \%$ of estimated cases 29.1 death in Africa and 31\% , 30.9 for estimated cases and death in the world.

Table (8) Estimated Malaria cases and death in the basin Nile region between 2000-2010. 
GIS-Based for Mapping Malaria Ris...

العدد الثامن والثلاثون

\begin{tabular}{|l|l|l|l|l|l|l|l|l|l|l|}
\hline \multirow{2}{*}{ Year } & \multicolumn{3}{|l|}{ Basin Nile } & \multicolumn{3}{l|}{ African } & \multicolumn{2}{l|}{ \% African } & \multicolumn{2}{l|}{ World the world\% } \\
\cline { 2 - 11 } & $\begin{array}{l}\text { Cases } \\
\text { million }\end{array}$ & $\begin{array}{l}\text { Death } \\
\text { thousand }\end{array}$ & $\begin{array}{l}\text { Cases } \\
\text { million }\end{array}$ & $\begin{array}{l}\text { Death } \\
\text { thousand }\end{array}$ & $\begin{array}{l}\text { Cases } \\
\text { million }\end{array}$ & $\begin{array}{l}\text { Death } \\
\text { thousand }\end{array}$ & $\begin{array}{l}\text { Cases } \\
\text { million }\end{array}$ & $\begin{array}{l}\text { Death } \\
\text { thousand }\end{array}$ & $\begin{array}{l}\text { Cases } \\
\text { million }\end{array}$ & $\begin{array}{l}\text { Death } \\
\text { thousand }\end{array}$ \\
\hline 2000 & 69.8 & 212.8 & 204 & 68000 & 342 & 31.3 & 238 & 736 & 29.3 & 28.9 \\
\hline 2010 & 60.9 & 134.4 & 215 & 597 & 28.3 & 22.5 & 215 & 484 & 24 & 22.6 \\
\hline 2019 & 71 & 126.5 & 215 & 384 & 33 & 29.1 & 229 & 409 & 31 & 30.9 \\
\hline
\end{tabular}

Source:

- The cases in 2000 represent 69.8 million cases and 212.8 thousand deaths, that decreased in 2010 to 60.9 million with decreasing rate 12.8 in estimated cases 36.8 in the deaths.

- The estimated cases in African regions has increased and Nile basin also increased because of the fast increasing population especially who live in the tropical regions in 2019.

- The African region accounted for $94 \%$ of cases and deaths in the world and it decreased to 43.5 between 2000-2019 and also it decreased in the death up to 44.2 as a result of medical progress in treating Malaria cases. 


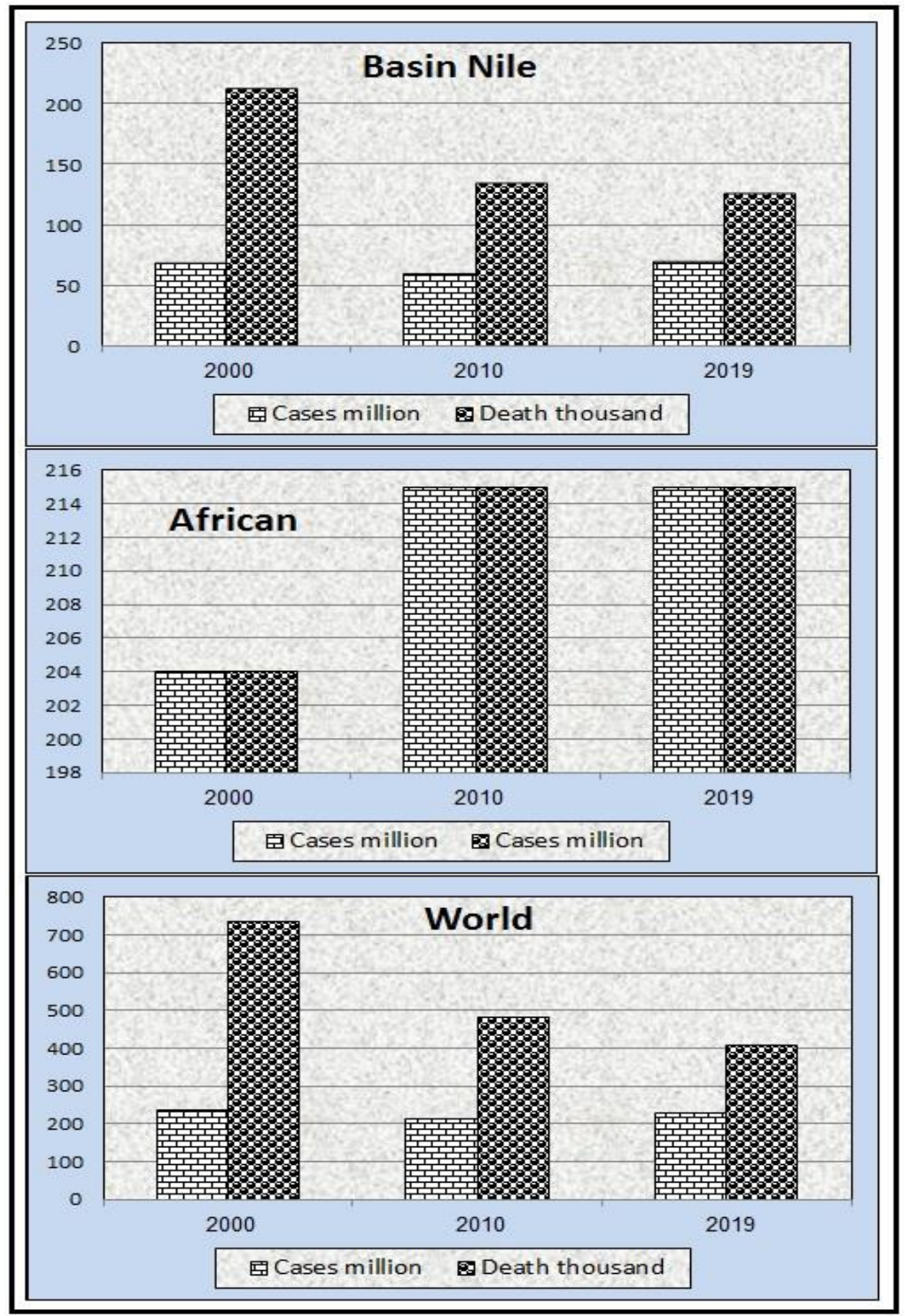

Figure () 


\section{Cases and population at risk}

As it Shaw in table (9) and fig. (4) Estimated and confirmed cases in 2010 with comparison of 2014.

Table (9)The confirmed and estimated malaria in the Nile basin countries between 2010-2018.

\begin{tabular}{|l|l|l|l|l|l|l|l|l|}
\hline \multirow{2}{*}{ Country } & \multicolumn{4}{|l|}{ Confirmed Malaria } & \multicolumn{3}{|c|}{ Estimated cases } \\
\cline { 2 - 9 } & 2010 & $\%$ & $\mathbf{2 0 1 9}$ & $\%$ & $\mathbf{2 0 1 0}$ & $\%$ & $\mathbf{2 0 1 9}$ & $\%$ \\
\hline Burundi & 4.3 & $\mathbf{8 . 2}$ & $\mathbf{9 . 4}$ & $\mathbf{1 5 . 8}$ & $\mathbf{3 . 7}$ & $\mathbf{7}$ & $\mathbf{4 . 5}$ & $\mathbf{6 . 3}$ \\
\hline D. Congo & $\mathbf{9 . 5}$ & $\mathbf{1 8 . 1}$ & $\mathbf{2 1 . 9}$ & $\mathbf{3 6 . 7}$ & $\mathbf{1 9 . 2}$ & $\mathbf{3 6 . 3}$ & $\mathbf{2 8 . 3}$ & $\mathbf{3 9 . 9}$ \\
\hline Eriteria & $\mathbf{0 . 5}$ & $\mathbf{1}$ & $\mathbf{0 . 1}$ & $\mathbf{0 . 2}$ & $\mathbf{0 . 2}$ & $\mathbf{0 . 4}$ & $\mathbf{0 . 2}$ & $\mathbf{0 . 3}$ \\
\hline Rwanda & $\mathbf{0 . 6}$ & $\mathbf{1 . 1}$ & $\mathbf{3 . 5}$ & $\mathbf{5 . 9}$ & $\mathbf{3 . 1}$ & $\mathbf{5 . 9}$ & $\mathbf{4 . 6}$ & $\mathbf{6 . 5}$ \\
\hline Uganda & $\mathbf{1 2 . 9}$ & $\mathbf{2 4 . 6}$ & $\mathbf{4 . 7}$ & $\mathbf{7 . 9}$ & $\mathbf{6 . 6}$ & $\mathbf{1 2 . 5}$ & $\mathbf{1 1 . 6}$ & $\mathbf{1 6 . 3}$ \\
\hline Tanzania & $\mathbf{1 2 . 9}$ & $\mathbf{2 4 . 6}$ & $\mathbf{6 . 4}$ & $\mathbf{1 0 . 7}$ & $\mathbf{6}$ & $\mathbf{1 1 . 3}$ & $\mathbf{6 . 4}$ & $\mathbf{9}$ \\
\hline Ethiopia & $\mathbf{4 . 1}$ & $\mathbf{7 . 8}$ & $\mathbf{1}$ & $\mathbf{1 . 7}$ & $\mathbf{8 . 1}$ & $\mathbf{9 . 6}$ & $\mathbf{5 . 3}$ & $\mathbf{7 . 5}$ \\
\hline Kenya & $\mathbf{6 . 1}$ & $\mathbf{1 1 . 7}$ & $\mathbf{5}$ & $\mathbf{8 . 4}$ & $\mathbf{3 . 2}$ & $\mathbf{6}$ & $\mathbf{3}$ & $\mathbf{4 . 2}$ \\
\hline S. Sudan & - & & $\mathbf{4}$ & $\mathbf{6 . 7}$ & $\mathbf{3 . 8}$ & $\mathbf{7 . 2}$ & $\mathbf{4 . 8}$ & $\mathbf{6 . 8}$ \\
\hline Sudan & $\mathbf{1 . 5}$ & $\mathbf{2 . 9}$ & $\mathbf{3 . 6}$ & $\mathbf{6}$ & $\mathbf{2}$ & $\mathbf{3 . 8}$ & $\mathbf{2 . 3}$ & $\mathbf{3 . 8}$ \\
\hline Total & $\mathbf{5 2 . 4}$ & $\mathbf{1 0 0}$ & $\mathbf{5 9 . 6}$ & $\mathbf{1 0 0}$ & $\mathbf{5 2 . 9}$ & $\mathbf{1 0 0}$ & $\mathbf{7 1}$ & $\mathbf{1 0 0}$ \\
\hline
\end{tabular}

Source: - 1- WHO: World Health Statistics,2010.

2-WHO: World Health Statistics, 2019. 


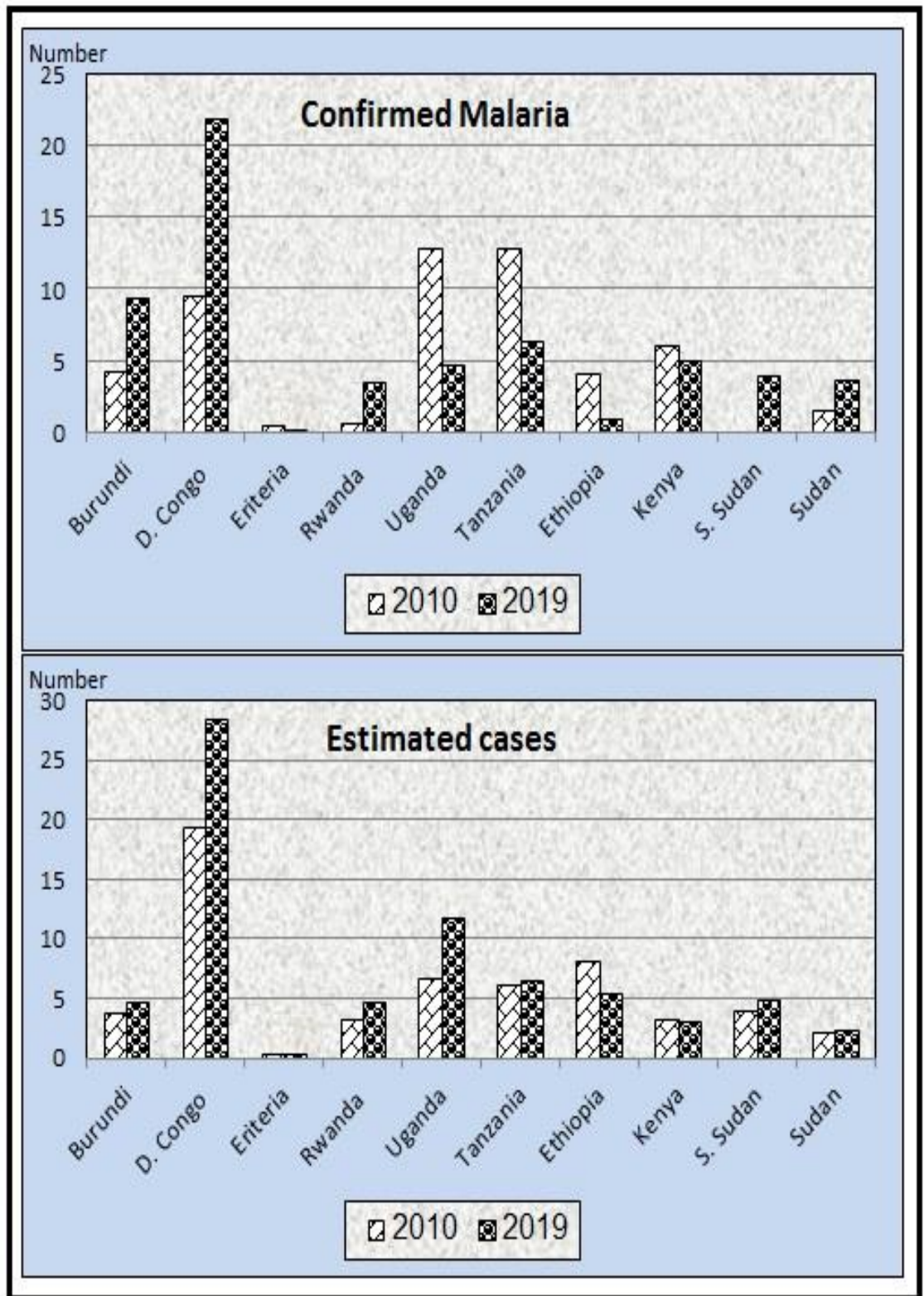

Figure ()

Malaria in 2019 in comparison with 2010 
- The population in the basin Nile countries were 339.3 million and increased to 435.3 million people with an increase equal $28.3 \%$ and that number represent $41.6 \%$ from the total of population in Africa.

- The suspect population of Malaria equal 69.9 million in 2010 that represent $20.6 \%$ from the population and the number has increased to 95.6 million that represent $22 \%$ for the population with an increase rate equal $36.8 \%$ than 2010 in the suspect cases of Malaria.

Population dominator for suspected and Malaria risk between 2010-2019 (million)

\begin{tabular}{|c|c|c|c|c|c|c|c|c|c|c|c|}
\hline \multirow[t]{2}{*}{$\begin{array}{l}\text { Countr } \\
\mathbf{y}\end{array}$} & \multicolumn{3}{|c|}{ Population No. } & \multicolumn{4}{|c|}{$\begin{array}{l}\text { Population of Malaria } \\
\text { suspect }\end{array}$} & \multicolumn{4}{|c|}{ Population at risk } \\
\hline & 2019 & $\%$ & 2010 & $\begin{array}{l}201 \\
0\end{array}$ & $\%$ & $\begin{array}{l}201 \\
9\end{array}$ & $\%$ & 2010 & $\%$ & 2019 & $\%$ \\
\hline $\begin{array}{l}\text { Burun } \\
\text { di }\end{array}$ & 11.5 & 2.6 & 8.8 & 5.6 & 7 & 8.6 & 9 & 8.8 & 3.6 & 11.5 & 4 \\
\hline $\begin{array}{l}\text { D.Con } \\
\text { go }\end{array}$ & 86.6 & $\begin{array}{l}19 . \\
9\end{array}$ & 67.5 & 10.6 & $\begin{array}{l}15 . \\
2\end{array}$ & 32.1 & $\begin{array}{l}33 . \\
6\end{array}$ & 65 & $\begin{array}{l}27 . \\
2\end{array}$ & 84.2 & $\begin{array}{l}29 . \\
2\end{array}$ \\
\hline Eretria & 3.5 & 0.8 & 3.3 & 1 & 1.4 & 0.2 & 0.2 & 2.1 & 0.9 & 2.5 & 0.9 \\
\hline $\begin{array}{l}\text { Rwand } \\
\text { a }\end{array}$ & 12.6 & 2.9 & 10.3 & 6 & 8.6 & 5.7 & 6 & 11.7 & 4.9 & 12.6 & 4.3 \\
\hline $\begin{array}{l}\text { Ugand } \\
\text { a }\end{array}$ & 44.3 & $\begin{array}{l}10 . \\
2\end{array}$ & 34.5 & 15.3 & $\begin{array}{l}21 . \\
9\end{array}$ & 16.4 & $\begin{array}{l}17 . \\
2\end{array}$ & 34.3 & $\begin{array}{l}14 . \\
4\end{array}$ & 44.3 & $\begin{array}{l}15 . \\
4\end{array}$ \\
\hline $\begin{array}{l}\text { Tanza } \\
\text { nia }\end{array}$ & 58 & $\begin{array}{l}13 . \\
3\end{array}$ & 46.2 & 15.1 & $\begin{array}{l}21 . \\
6\end{array}$ & 12.9 & $\begin{array}{l}13 . \\
5\end{array}$ & 39.2 & $\begin{array}{l}15 . \\
2\end{array}$ & 42.2 & $\begin{array}{l}14 . \\
6\end{array}$ \\
\hline $\begin{array}{l}\text { Ethiopi } \\
\text { a }\end{array}$ & $\begin{array}{l}112 . \\
1\end{array}$ & $\begin{array}{l}25 . \\
8\end{array}$ & 84.7 & 5.4 & 7.7 & 9.7 & 7 & 31 & 13 & 30.5 & $\begin{array}{l}10 . \\
6\end{array}$ \\
\hline Kenya & 52.6 & $\begin{array}{l}12 . \\
2\end{array}$ & 41.6 & 7.6 & $\begin{array}{l}10 . \\
9\end{array}$ & 0.1 & 0.1 & 32 & $\begin{array}{l}13 . \\
4\end{array}$ & 36.9 & $\begin{array}{l}12 . \\
8\end{array}$ \\
\hline $\begin{array}{l}\text { S- } \\
\text { Sudan }\end{array}$ & 11.1 & 2.5 & 8 & 0.9 & 1.3 & 5.3 & 5.5 & 8 & 3.3 & 11.1 & 3.8 \\
\hline Sudan & 42.8 & 9.8 & 34.4 & 2.4 & 3.4 & 7.6 & 7.9 & 9.8 & 4.1 & 12.4 & 4.3 \\
\hline Total & $\begin{array}{l}435 . \\
3\end{array}$ & 100 & $\begin{array}{l}339 . \\
3\end{array}$ & 9.9 & 100 & 95.6 & 100 & $\begin{array}{l}238 . \\
9\end{array}$ & 100 & $\begin{array}{l}208 . \\
2\end{array}$ & 100 \\
\hline
\end{tabular}

Source: - 1- WHO: World Health Statistics,2010. 
2-WHO: World Health Statistics, 2019.

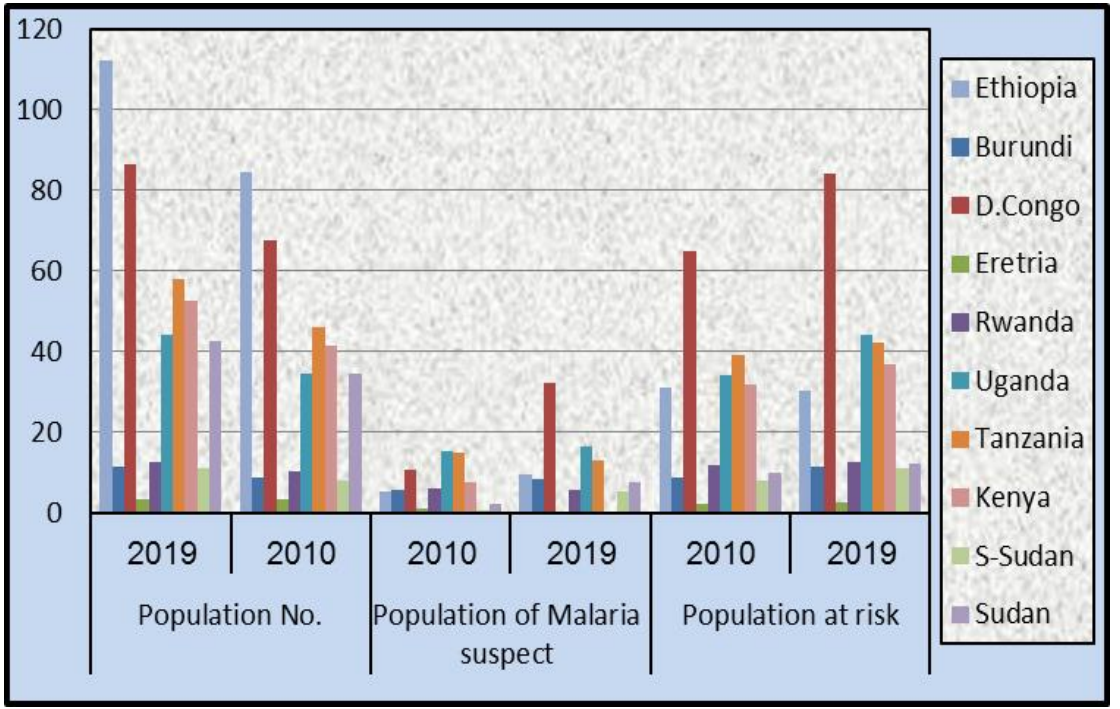

Figure ()

- Nearly 239.9 million were at risk of Malaria in 2010 and increased to 288.2 million in 2019 with an increase rate equal 20.1 and D.Congo occupied the first rank in suspected

\section{Estimating and confirming Malaria deaths between} 2010-2019

Malaria causes much damages represent in the deaths of more than 82189 in Africa in 2019. From the table and fig. ( ) that indicates. 
GIS-Based for Mapping Malaria Ris... العدد الثامن والثلاثون

\section{Table () estimating and confirming Malaria deaths} between 2010-2019 in Nile basin countries

\begin{tabular}{|l|l|l|l|l|l|l|l|l|}
\hline Country & \multicolumn{4}{|l}{ Estimated deaths } & \multicolumn{3}{l|}{ Confirmed deaths } \\
\hline & $\mathbf{2 0 1 0}$ & $\boldsymbol{\%}$ & $\mathbf{2 0 1 9}$ & $\boldsymbol{\%}$ & $\mathbf{2 0 1 0}$ & $\boldsymbol{\%}$ & $\mathbf{2 0 1 9}$ & \% \\
\hline Burundi & $\mathbf{5 1 2 4}$ & $\mathbf{3 . 4}$ & $\mathbf{5 1 6 3}$ & $\mathbf{4 . 3}$ & $\mathbf{3 2 1 1}$ & $\mathbf{1 0 . 6}$ & $\mathbf{3 3 1 6}$ & $\mathbf{1 0 . 8}$ \\
\hline D.Congo & $\mathbf{4 3 4 2 0}$ & $\mathbf{3 6 . 8}$ & $\mathbf{4 4 0 0 0}$ & $\mathbf{3 7 . 4}$ & $\mathbf{1 3 0 0 1}$ & $\mathbf{4 3}$ & $\mathbf{1 3 0 7}$ & $\mathbf{2 4 . 6}$ \\
& & & & & & & $\mathbf{2}$ & \\
\hline Eretria & $\mathbf{4 9 0}$ & $\mathbf{. 4}$ & $\mathbf{4 3 7}$ & $\mathbf{4}$ & $\mathbf{2 8 0}$ & $\mathbf{0 . 4}$ & $\mathbf{3 0 0}$ & $\mathbf{1 . 0}$ \\
\hline Rwanda & $\mathbf{3 5 0 7}$ & $\mathbf{3 .}$ & $\mathbf{3 2 8 8}$ & $\mathbf{2 . 8}$ & $\mathbf{2 1 1}$ & $\mathbf{0 . 7}$ & $\mathbf{2 2 4}$ & $\mathbf{. 6}$ \\
\hline Uganda & $\mathbf{1 3 6 3 0}$ & $\mathbf{1 1 . 6}$ & $\mathbf{1 3 5 7 6}$ & $\mathbf{1 1 . 6}$ & $\mathbf{5 0 0 1}$ & $\mathbf{1 6 . 5}$ & $\mathbf{5 0 2 7}$ & $\mathbf{1 6 . 4}$ \\
\hline Tanzania & $\mathbf{2 4 6 6 1}$ & $\mathbf{2 0 . 9}$ & $\mathbf{2 1 7 5 6}$ & $\mathbf{1 8 . 5}$ & $\mathbf{1 0 6 2}$ & $\mathbf{3 . 5}$ & $\mathbf{1 1 7 1}$ & $\mathbf{3 . 8}$ \\
\hline Ethiopia & $\mathbf{5 4 1 0}$ & $\mathbf{4 . 9}$ & $\mathbf{5 6 2 0}$ & $\mathbf{4 . 8}$ & $\mathbf{2 0 0}$ & $\mathbf{. 7}$ & $\mathbf{2 1 3}$ & $\mathbf{0 . 7}$ \\
\hline Kenya & $\mathbf{1 2 6 2 2}$ & $\mathbf{1 0 . 8}$ & $\mathbf{1 2 6 5 0}$ & $\mathbf{1 0 . 8}$ & $\mathbf{8 4 7}$ & $\mathbf{2 . 8}$ & $\mathbf{8 5 8}$ & $\mathbf{2 . 8}$ \\
\hline S-Sudan & $\mathbf{5 1 1 2}$ & $\mathbf{4 . 4}$ & $\mathbf{5 3 4 2}$ & $\mathbf{4 . 5}$ & $\mathbf{4 7 9 2}$ & $\mathbf{1 5 . 8}$ & $\mathbf{4 8 7 3}$ & $\mathbf{1 5}$ \\
\hline Sudan & $\mathbf{4 1 2 1}$ & $\mathbf{3 . 4}$ & $\mathbf{5 6 1 4}$ & $\mathbf{4 . 8}$ & $\mathbf{1 6 4 1}$ & $\mathbf{5 . 5}$ & $\mathbf{1 6 6 3}$ & $\mathbf{5 . 4}$ \\
\hline & & $\mathbf{1 0 0}$ & & $\mathbf{1 0 0}$ & & $\mathbf{1 0 0}$ & & $\mathbf{1 0 0}$ \\
\hline & $\mathbf{1 1 8 0 9 2}$ & $\mathbf{2 4 9}$ & $\mathbf{1 1 7 4 5}$ & $\mathbf{3 0 . 6}$ & $\mathbf{3 0 2 4 6}$ & $\mathbf{3 0 7 1 7}$ & $\mathbf{3 7 . 4}$ & \\
& & & $\mathbf{0}$ & & & & & \\
\hline Africa & $\mathbf{5 4 2 0 0 0}$ & $\mathbf{1 0 0}$ & $\mathbf{3 8 4 0 0}$ & & & & $\mathbf{8 2 1 8}$ & \\
& & & & & & & $\mathbf{9}$ & \\
\hline
\end{tabular}

Source: - 1- WHO: World Health Statistics, 2010.

2-WHO: World Health Statistics, 2019. 


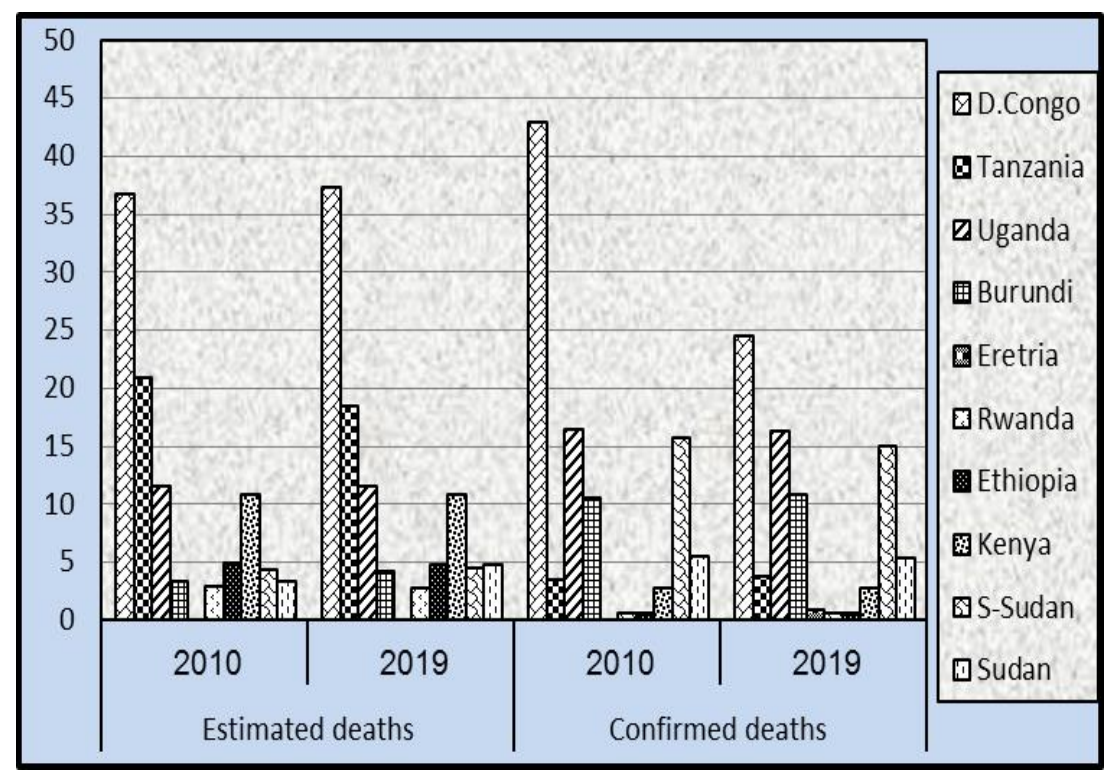

- The estimated death of Malaria is nearly 38400 in the continent and the Nile basin countries represent $30.6 \%$ from the estimated cases in 2019 and in 2010 the estimated cases arrived to $21.9 \%$ from the continent.

- The confirmed death has increased from 30246 in 2010 to 30717 thousand in 2019 although the increasing of population number and D. Congo took the first rank in estimated and confirmed death.

\section{IV- The kind of malaria mosquitoes}

Malaria remains the most complex health problem, that facing humanity with 300 to 500 million cases and 2 to 3 million deaths per year. About $90 \%$ of the malaria deaths happen in sub-sharan Africa and many countries of the Nile basin, because of infection of plasmodium falciparum. The most dangerous of the four human malaria parasites (P. 
falciparum, p. Ovale P. Vivax, P. malaria) accounting 1.4 to 2.6 million death per year in this region (Steketeee RW., 2001, p. 32-34). The mosquito Anopheles Gambia is the widest spread in the region and most difficult to control. In this, Region people receive 200 to 350 infective bites per year (United Nation, 2010. the region have six spies of the Anopheles Gambia being the most affected vectors of human malaria, (FAO, 2003).

- P. falciparum burden stated that $90 \%$ of the African and Nile basin is concentrated in them. The scientific researches proved that it settled in the continent since 6000 years ago, P. falciparum population expanded in the continent and spread in the other continents, with the growth of the population and subsequent Diasporas

Table (10) The case of malaria according to sort of Mosquito 2010-2019 in the basin Nile countries according to confirmed cases.

\begin{tabular}{|c|c|c|c|c|c|c|}
\hline \multirow{2}{*}{\multicolumn{2}{|c|}{$\begin{array}{l}\text { Countries } \\
\text { Year }\end{array}$}} & \multirow{3}{*}{$\begin{array}{l}\text { Indigenous } \\
\text { No. } \\
4.3\end{array}$} & \multicolumn{2}{|c|}{ P. Falciparum } & \multicolumn{2}{|c|}{ p.vivax } \\
\hline & & & \multirow{2}{*}{$\begin{array}{l}\text { No. } \\
4.1\end{array}$} & \multirow{2}{*}{$\begin{array}{l}\%^{\prime} \\
95.3\end{array}$} & \multirow{2}{*}{$\begin{array}{l}\mathrm{N} \\
0.3\end{array}$} & \multirow{2}{*}{$\begin{array}{l}\% \\
0.7\end{array}$} \\
\hline & 2010 & & & & & \\
\hline Burundi & 2019 & 9.4 & 9 & 95.7 & 0.4 & 4.3 \\
\hline \multirow{2}{*}{ D-Congo } & 2010 & 9.5 & 7.4 & 77.9 & 2.1 & 22.1 \\
\hline & 2019 & 21.9 & 20.3 & 92.7 & 1.6 & 7.3 \\
\hline \multirow{2}{*}{ Eriteria } & 2010 & 0.5 & 4 & 80 & 2 & 2 \\
\hline & 2019 & 0.1 & 0.1 & 100 & - & - \\
\hline \multirow{2}{*}{ Ethiopia } & 2010 & 4.1 & 0.3 & 73.2 & 1.1 & 26.8 \\
\hline & 2019 & 1 & 0.7 & 70 & 0.3 & 30 \\
\hline \multirow{2}{*}{ Kenya } & 2010 & 6.1 & 5.9 & 96.7 & 0.2 & 3.3 \\
\hline & 2019 & 5 & 5 & 100 & - & - \\
\hline \multirow{2}{*}{ Rwanda } & 2010 & 0.6 & 0.5 & 83 & 0.1 & 17 \\
\hline & 2019 & 3.5 & 3.2 & 91.4 & 0.3 & 8.6 \\
\hline S-Sudan & 2010 & - & - & - & 0.3 & - \\
\hline
\end{tabular}




\begin{tabular}{|c|c|c|c|c|c|c|}
\hline & 2019 & 4 & 3 & 75 & 1 & 25 \\
\hline \multirow{2}{*}{ Uganda } & 2010 & 12.9 & 11 & 85.3 & 1.9 & 14.7 \\
\hline & 2019 & 4.7 & 4.2 & 89.4 & 0.5 & 10.6 \\
\hline \multirow{2}{*}{ Tanzania } & 2010 & 12.9 & 11.2 & 86.8 & 1.7 & 13.2 \\
\hline & 2019 & 6.4 & 5.3 & 82.8 & 1.1 & $17 . .2$ \\
\hline \multirow[t]{2}{*}{ Sudan } & 2010 & 1.5 & 1.2 & 80 & 0.3 & 20 \\
\hline & 2019 & 3.6 & 2.9 & 80.6 & 0.7 & 19.4 \\
\hline
\end{tabular}

Source:-

Facilitated by the knowing of agriculture. P. falciparum is responsible for transmission of many harmful diseases especially Malaria. It is known to affect and infect over 700 million deaths including the Nile basin countries and Africa (WHO, 2016). Many results proved that. These mosquitos' vectors and its relationship with rainfall also in the Nile basin region, the higher number of anopheles spices in the area as a result of the favorable tropical weather and breeding conditions from the table (10) we can follow:

- Anopheles falciparum was the most predominant in most of the Nile basin total countries 2010 with $95.3 \%$ in Burundi, 96.7\% in Kenya and $91.4 \%$ in Rwanda in 2019 with $95.7 \%$ in Burundi, $92.7 \%$ in D.Congo, $100 \%$ of Eretria and Kenya because of the presence of high temperature, rain fall and other environment that help in the growth of these mosquitoes.

- p. vivax spread in Ethiopia, Uganda and South Sudan because the condition is suitable for growth. It required heavy rains with water that creates breeding to grow. It required heavy rains that creates breeding sites for female mosquitoes to lay eggs, and in these errantries save high humidity that help adult mosquitoes daily survival and it 
is responsible for $19.4 \%$ of confirmed Malaria in the Nile basin countries.

- The Anopheles gambiae is not breeding in urban areas with a fewer appropriate breeding sites. The people who live in the urban areas are on average 10 times more likely to have an infective bite than the other who are in the rural parts. Nearly $50 \%$ percent of the Nile Basin's population were urban dwellers (United Nation Division 2010) several and highly successful vector control programs in Africa and the Nile Basin had significant effects through transmission (Bradley 1991, p.63). Recently such as Ethiopia, Uganda, South Sudan and Tanzania do their best to reduce transmission in areas, which are classified as prone to transmission. It will not be possible to account for all local vector control activities.

\section{V- the social characteristics of infected people}

Malaria impacted in pregnant, children and causes troubles to the sick people as the following:

\section{1- Estimating of Malaria specific morality by age}

There are many studies estimate of Malaria morality under five years living and up conditions of stable transmission were used from demographic surveillance system (DSS) sites in Burundi, Kenya, Tanzania and DCongo. The Malaria- specific mortality rate among these 
countries communities was 9.5 per 1000 children per year represented $28.5 \%$ of all mortality among children under five.

It ranges between 1.6-1.8 per 1000per year representing $52.4 \%$ of all deaths in the age 5 to 14 years. Among adult population rates were 0.7 per 1000 per year, or $6 \%$ of all death among population age 15 years to older as it shown in the table.

Malaria-specific morality in children is nearly 3.6 times higher in areas of stable Malaria in the Basin Nile countries excluding Egypt. It's notable that morality decreased with increasing age. The morality rates of all ages from P.Falciparum in this area, this infection with P.Falciparum may has cause for the death of 77350 cases in Africa and 33211 in the Basin Nile in 2018 (WHO,2018).

\section{The death of children aged under 5 years between 2010-2019.}

- Analysis of the children death aged under 5 regards a regressive between 2010 to 2019 equal $69.1 \%$ between the nine years, there 37790 children death in 2010 decreased to 11684 death children case in 2019, and this reduction as a result of intensive care of children and the medical advancing in treating Malaria.

Table () the reported infant death in the Nile basin countries connected with Malaria 2010-2019. 
GIS-Based for Mapping Malaria Ris...

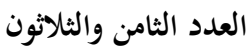

\begin{tabular}{|c|c|c|c|c|c|c|}
\hline \multirow[t]{2}{*}{ Country } & \multicolumn{2}{|l|}{2010} & \multirow{2}{*}{$\begin{array}{l}\% \text { of } \\
\text { total } \\
\text { death }\end{array}$} & \multicolumn{2}{|l|}{2019} & \multirow{2}{*}{$\begin{array}{l}\% \text { of } \\
\text { total } \\
\text { death }\end{array}$} \\
\hline & numbers & $\begin{array}{l}\text { Total } \\
\text { death }\end{array}$ & & number & $\begin{array}{l}\text { total } \\
\text { death }\end{array}$ & \\
\hline Burundi & 1121 & 2677 & 41.9 & 1416 & 3316 & 4.7 \\
\hline D. Congo & 11511 & 23476 & 44.2 & 4721 & 13072 & 3.1 \\
\hline Kenya & 12502 & 26017 & 44.1 & 312 & 858 & 36.4 \\
\hline Tanzania & 7351 & 15915 & 46.2 & 472 & 1171 & 40.3 \\
\hline Uganda & 3491 & 8431 & 41.4 & 1812 & $\mathbf{5 0 2 7}$ & 36 \\
\hline Ethiopia & 543 & 1581 & 34.3 & 81 & 213 & 38 \\
\hline $\begin{array}{l}\text { South } \\
\text { Sudan }\end{array}$ & 580 & 1053 & 55.1 & 2181 & 4873 & 44.8 \\
\hline Sudan & 410 & 1023 & 40.1 & 605 & 1663 & 36.4 \\
\hline Rwanda & 670 & 670 & 40.3 & 83 & 224 & 37.1 \\
\hline Eretria & 11 & 27 & 40.7 & 1 & 3 & 33.3 \\
\hline Total & 37790 & 80870 & 46.7 & 11684 & 30432 & 38.4 \\
\hline Africa & 74356 & 150383 & 49.4 & 32347 & 82189 & 39.4 \\
\hline
\end{tabular}

Source: World Health Organization, 2019.

- Most of the Nile countries have a reduction in the children death except Burundi and South Sudan because of wars and political troubles inside the two countries.

- The number of children death represent $37 \%$ from the children's death in the Africa in 2019 and it has a reduction from $50.8 \%$ in the children's death in 2010 . 


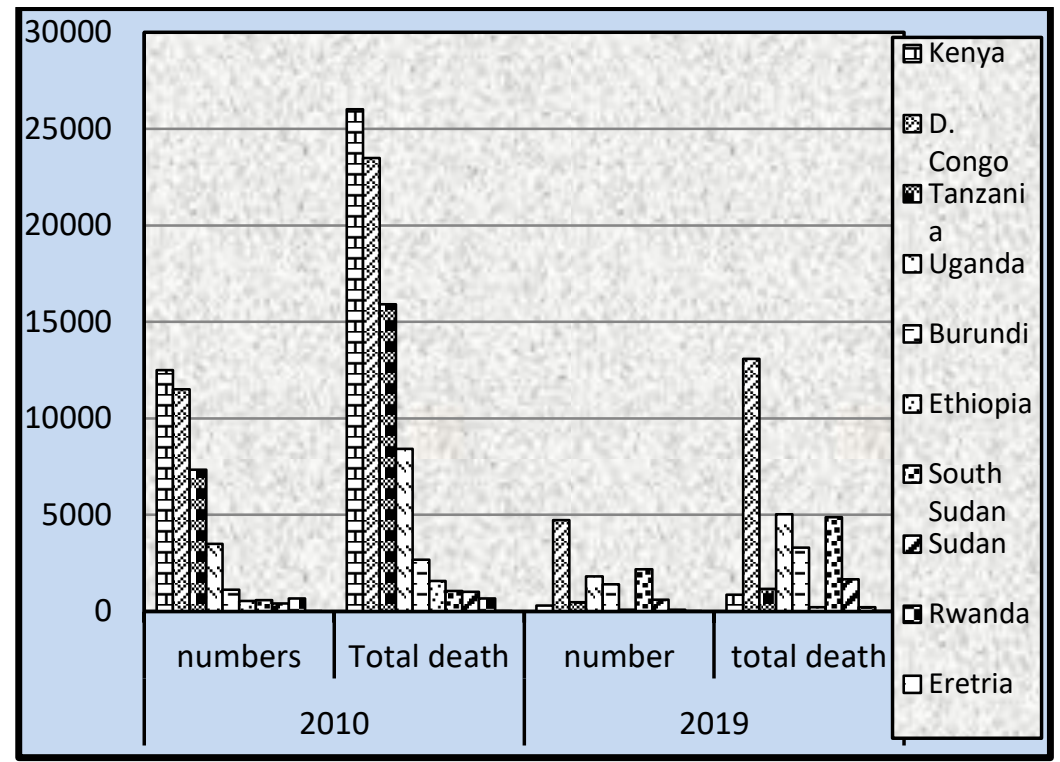

Figure ()

\section{The Malaria during pregnancy}

There are many studies described the malaria infection during pregnancy in Africa. Pregnant women experience relatively little Malaria:-

Specific morbidity such as fever, anemia placental sequestration of the parasite. These effects operate a cross a broader range of endemic ties used to morbid and fatal risk among non-pregnant women.10 maternal mortality with a relative risk for mortality million 1.4 for moderate anemia and 3.6 million for severe anemia has been a witness to be contributor ( Braban, Hakim and pelletier,2001,p.131). Some studies estimate that Malaria contributes to maternal anemia and $9 \%$ of anemia in pregnant women connected with maternal mortality in the tropical Nile Basin countries. 
The newborn characteristic with low with low weight (less than $2.500 \mathrm{~g}$ ) the contribution if Malaria during pregnancy to low birth weight and subsequent mortality in the first year of life has been estimated to range from 4 to $9 \%$ of infant mortality. In this region there may have been between 82000 and 17000 infant deaths indirectly attributable to Malaria in pregnancy as it shown in table (11), that indicate the following:

Table (11) number of infected pregnant and number of symptoms of Malaria 2019

\begin{tabular}{|c|c|c|c|c|c|c|c|c|}
\hline \multirow{2}{*}{$\begin{array}{l}\text { Countr } \\
\mathbf{y}\end{array}$} & \multirow[b]{2}{*}{$\begin{array}{l}\text { Infecte } \\
\text { d } \\
\text { pregna } \\
\text { nt } \\
\text { (million } \\
\text { ) }\end{array}$} & \multirow[t]{2}{*}{$\%$} & \multicolumn{3}{|c|}{ Moderate anemia } & \multicolumn{3}{|c|}{ Severe anemia } \\
\hline & & & $\begin{array}{l}\text { Numbe } \\
\text { rs }\end{array}$ & $\%$ & $\begin{array}{l}\text { \% of } \\
\text { pregna } \\
\text { nt }\end{array}$ & $\begin{array}{l}\text { numbe } \\
\text { rs }\end{array}$ & $\%$ & $\begin{array}{l}\% \text { of } \\
\text { pregna } \\
\text { nt }\end{array}$ \\
\hline Burndy & 1.3 & 5.3 & 0.4 & 5.9 & 30.8 & 0.9 & 5.7 & 69.2 \\
\hline $\begin{array}{l}\text { D. } \\
\text { Congo }\end{array}$ & 4.5 & $\begin{array}{l}18 . \\
4\end{array}$ & 1.2 & $\begin{array}{l}17 . \\
6\end{array}$ & 26.7 & 3.3 & $\begin{array}{l}18 . \\
6\end{array}$ & 73.3 \\
\hline Eriteria & 0.2 & 0.8 & 0.1 & 1.4 & 50 & 0.1 & 0.6 & 50 \\
\hline $\begin{array}{l}\text { Rwand } \\
\text { a }\end{array}$ & 1.2 & 4.9 & 0.5 & 7.4 & 41.7 & 0.7 & 4 & 58.2 \\
\hline Uganda & 3.7 & $\begin{array}{l}15 . \\
1\end{array}$ & 1.1 & $\begin{array}{l}16 . \\
2\end{array}$ & 29.7 & 2.6 & $\begin{array}{l}14 . \\
7\end{array}$ & 70.3 \\
\hline $\begin{array}{l}\text { Tanzan } \\
\text { ia }\end{array}$ & 3.8 & $\begin{array}{l}15 . \\
5\end{array}$ & 1.1 & $\begin{array}{l}16 . \\
2\end{array}$ & 28.9 & 2.7 & $\begin{array}{l}15 . \\
3\end{array}$ & 71.1 \\
\hline $\begin{array}{l}\text { Ethiopi } \\
\text { a }\end{array}$ & 2.2 & 9 & 0.6 & 8.8 & 27.3 & 1.6 & 9 & 72.7 \\
\hline Kenya & 2.6 & $\begin{array}{l}10 . \\
6\end{array}$ & 0.7 & $\begin{array}{l}10 . \\
3\end{array}$ & 26.9 & 1.9 & $\begin{array}{l}10 . \\
7\end{array}$ & 73.1 \\
\hline $\begin{array}{l}\text { South } \\
\text { Sudan }\end{array}$ & 2 & 8.2 & 0.4 & 5.9 & 20 & 1.6 & 9 & 80 \\
\hline Sudan & 3 & $\begin{array}{l}12 . \\
2\end{array}$ & 0.7 & $\begin{array}{l}10 . \\
3\end{array}$ & 23.3 & 2.3 & 13 & 76.7 \\
\hline total & 24.5 & 100 & 6.8 & 100 & 27.8 & 27.8 & 100 & 72.2 \\
\hline
\end{tabular}

Source:- 


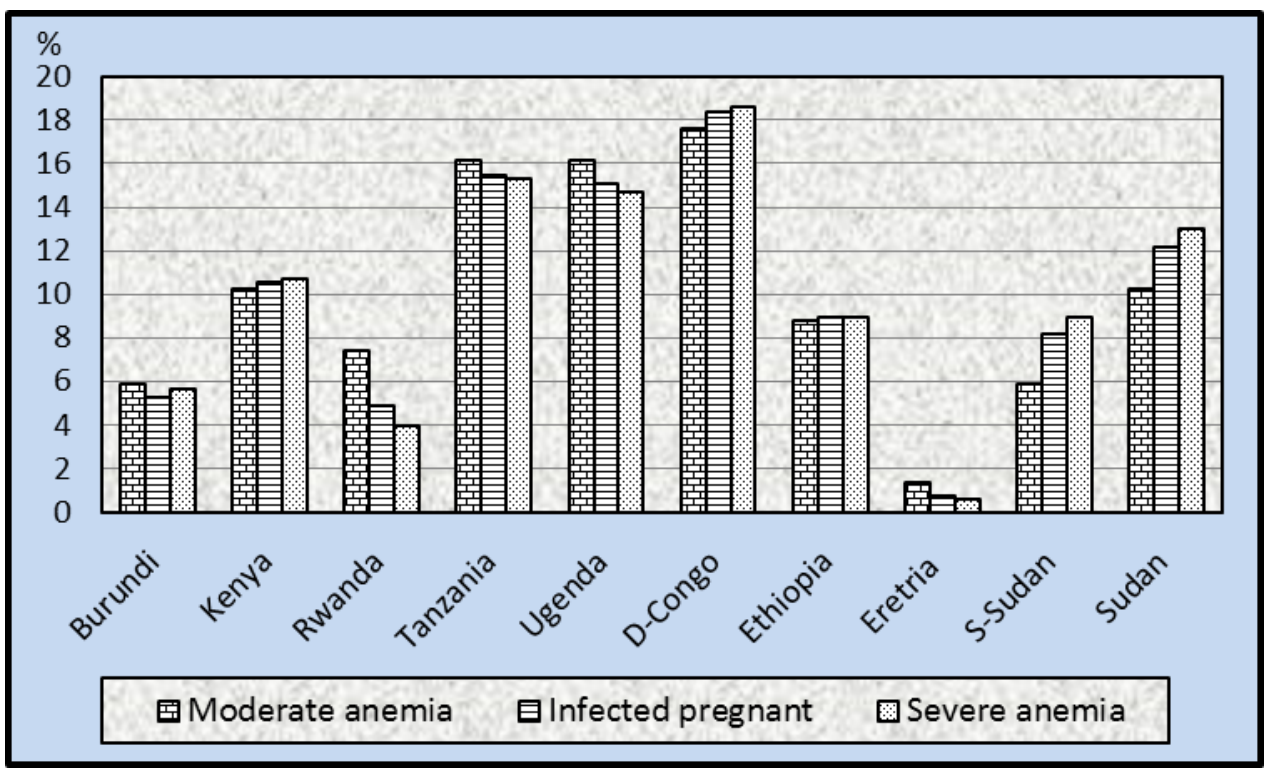

Figure (5)

- The infected pregnant of Malaria nearly 24.5 million women and represent $7.9 \%$ from the people at risk of Malaria.

- Nearly 6.8 million of them have Moderate Malaria anemia with a high percentage Burundi, D.Congo, Rwanda, Eriteria, Tanzania, Ethiopia and kenya that represent 30.8, 26.7, 50, 29.7,28.9,27.3,26.9 \% because of the spread of F.falciburum and most of their governments mange to treat the Moderate anemia of Malaria.

- The sever Malaria that may cause death to pregnant or low weight of the born are spread widely in south Sudan, Sudan , D.Congo ,Kenya, Ethiopia and Tanzania with a 
percentage equal $80,76.7,73.3,73.1,72.7,73.1 \%$ and represent 72.2 from the infected pregnant.

\section{The impact of Malaria on health}

\section{Anemia}

Very severe anemia is accompanied the children with malaria. Malaria is always difficult to diagnose on hospitals and clinical condition. Fever as a result of the infectious disease that caused by P.Falciparum, like acidosis and altered consciousness. The ill person, demonstrating the attendance of Malaria infection increases the symptoms according to infection that cannot exclude other diagnoses. Many detailed clinical studies in the Basin Nile hospital have described the routes to the disease and these contain cerbal involvement from sequestered infection in the vasculature of the brain, metabolic disturbances, respiratory distress and anemia

\section{Anemia}

For instance, we must define two major symptoms of Malaria, the First is cerbal Malaria (CM) and the second is severe Malaria anemia (SAM). CM is representing in patients in coma with many underlying causes, ranging from primarily neurological to a systemic metabolic disturbances (March; 1999, p.56). Severe anemia has many complex causes that is combining of rapid hemolysis during infection or may slow inside process compounded by anti-malaria medicine resistance. SMA is threating young children. 


\section{Neurologic Disability}

The Cerbal Malaria (CM) may available in most countries of the Nile Basin, it may cause the prolonged coma, and seizures are connected with neurological in survivals. This $\mathrm{CM}$ are available among all African children includes hemiparesis, severe deficit, hearing and seeing impairment, speech and nonverbal establishment difficulties and behavioral troubles. These symptoms are probable occur in nearly 5000 children each year in the basin Nile countries. Those children have a higher mortality risk. Most of the children death in eastern countries of the Nile basin.

\section{Mortality}

The great result of P.Falciparum infection include anemia that is exist in high-density parasitemia, low in the weight of the birth, late in growth and under nutrition.

Malaria infection can increase the severity of other comorbid infections disease through immune suppression across natural barriers to injection from the blood and tissue. The global burden of disease have ensured that each death happen in African countries. Fevers are spread in Africa and the usage of antimalarial drugs is prolific. 


\section{4- Malaria causes poverty:}

There is a correlation between regression of gross domestic product and the disease of Malaria as it has a significant impact on the economic growth. Nearly a half of the gross domestic product is lost in highly malaria risk endemic areas over 45 years as a result of Malaria. Although the shares of international donors. The national macroeconomic of the countries of the basin Nile failed to reduce the mechanism of these economic losses.

It seem to confirm that national levels of economic loss are composite of bearing economic burdens especially at the household level. It is estimated that the household cost of Malaria in the following table ()

Table () The household cost of Malaria between 1987-2019

\begin{tabular}{|l|l|l|l|}
\hline \multirow{2}{*}{ Country } & 1987 & 2015 & 2019 \\
\cline { 2 - 4 } & $\begin{array}{l}\text { Household cost } \\
\text { of Malaria (US } \\
\text { Dollar) }\end{array}$ & $\begin{array}{l}\text { Household cost } \\
\text { (US Dollar) }\end{array}$ & $\begin{array}{l}\text { Household cost } \\
\text { (US Dollar) }\end{array}$ \\
\hline Burundi & 9.8 & 16.7 & 28.3 \\
\hline Dr. Congo & 9.7 & 17.6 & 28.7 \\
\hline Eriteria & 8.5 & 17.5 & 28 \\
\hline Rwanda & 8.7 & 17.7 & 28 \\
\hline Uganda & 9.1 & 17.8 & 29 \\
\hline Tanzania & 9.3 & 17.6 & 28.6 \\
\hline Ethiopia & 8.7 & 16.9 & 28.7 \\
\hline Kenya & 8.9 & 17 & 28.7 \\
\hline South Sudan & 6 & 16 & 26.9 \\
\hline Sudan & 9.1 & 17.9 & 28.7 \\
\hline Average & 8.8 & 17.2 & 28.1 \\
\hline Africa & 8.2 & 17.2 & 28 \\
\hline
\end{tabular}


Source: - World Health Organization, various years, Geneva

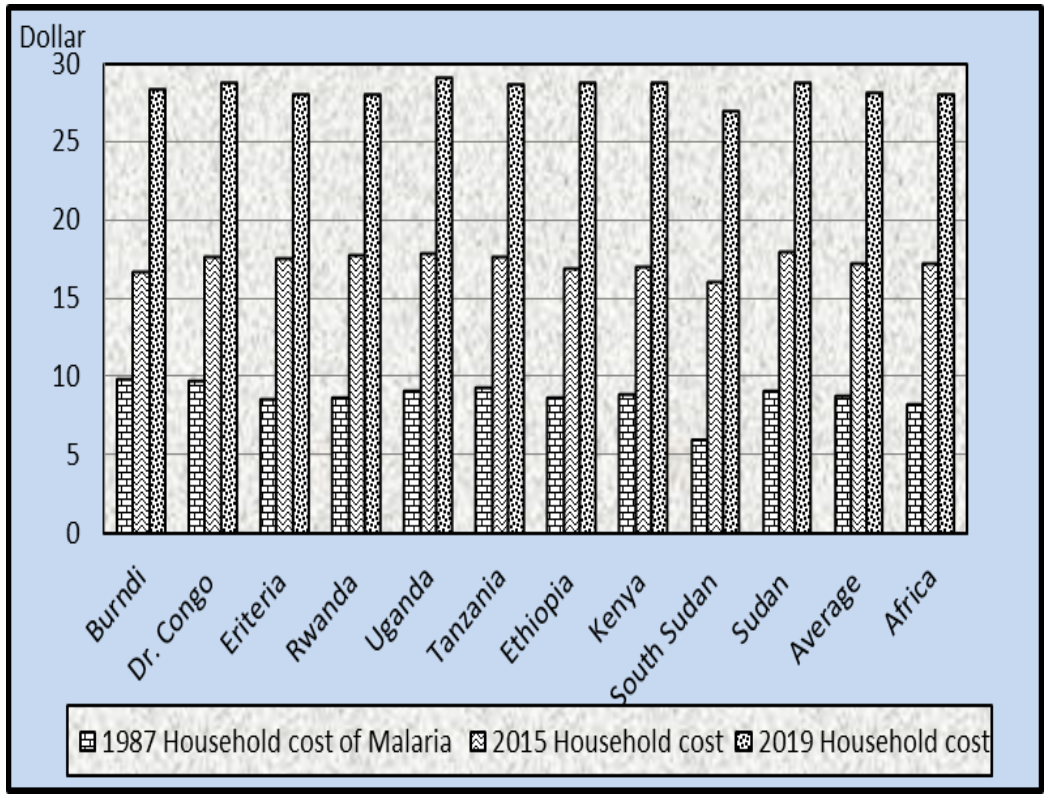

Figure (6)

- The household cost of Malaria in the Nile Basin countries nearly $8.8 \$$ and decreased to $8.2 \$$ in other African countries that was occurred indirectly as a result of forgone income connected with Malaria morbidity and mortality. The total estimated costs of US $\$ 0.4$ billion presents $0.7 \%$ of the gross domestic product of the economies in the Nile Basin countries.

- In 2015 the costs of the household Malaria has raised to 17.2 dollar with an increase equal 109.85 and it also kept 
raising to 28.1 dollar in 2019 with an increase equal $36.4 \%$ between $2015-2019$ and that posted by WHO.

- Microeconomic analyses of household economic burden are a fraction of macroeconomic analyses of national economic loss (Malaney, et.2004,p142) suggested that his variation might increase as a result of macroeconomic national burden include the household financial cost and ill-defined financial like trade, tourism, industry and other investments.

- This national poverty needs better definition and also the poor people are not able to prevent infection or they are not able to afford effective disease management. In Africa and the Nile Basin countries, Malaria is a dangerous disease of the rural population and their communities represented in their homes, which is very poor.

\section{The expenses of treatment Malaria}

It nearly cost 1260 million dollar to face Malaria in the basin Nile region as it shown in table () and shape () and from them indicate on the following:

- DR-Congo occupies the first rank of the Malaria treatment Expenses with 325.5 million Dollar represent $25.8 \%$ in the basin Nile region because of the increasing 
in the estimated Malaria cases in it, although the WHO share and various contributions. ${ }^{1}$

\section{Table () the expenses of treatment Malaria in 2019}

\begin{tabular}{|l|l|l|l|l|l|l|l|}
\hline \multirow{2}{*}{ Countries } & \multicolumn{2}{l|}{ Donars } & \multicolumn{2}{l|}{ Countries } & \multicolumn{2}{l|}{ total } & \\
\cline { 2 - 8 } & million & $\%$ & million & $\%$ & million & $\%$ & \\
\hline Burundi & $\mathbf{3 9 . 1}$ & $\mathbf{6 . 3}$ & $\mathbf{3 3 . 8}$ & $\mathbf{5 . 2}$ & $\mathbf{7 2 . 9}$ & $\mathbf{5 . 8}$ & $\mathbf{1 6 . 2}$ \\
\hline $\begin{array}{l}\text { DR- } \\
\text { Congo }\end{array}$ & $\mathbf{1 6 8 . 7}$ & $\mathbf{2 7 . 4}$ & $\mathbf{1 5 6 . 8}$ & $\mathbf{2 4 . 4}$ & $\mathbf{3 2 5 . 5}$ & $\mathbf{2 3 . 8}$ & $\mathbf{1 1 . 5}$ \\
\hline Eretria & $\mathbf{8 . 9}$ & $\mathbf{1 . 4}$ & $\mathbf{5 . 3}$ & $\mathbf{0 . 8}$ & $\mathbf{1 4 . 2}$ & $\mathbf{1 . 1}$ & $\mathbf{7 0 . 9}$ \\
\hline Ethiopia & $\mathbf{2 6 . 7}$ & $\mathbf{4 . 3}$ & $\mathbf{1 8 9 . 3}$ & $\mathbf{2 9 . 4}$ & $\mathbf{2 1 6}$ & $\mathbf{1 7 . 1}$ & $\mathbf{4 7}$ \\
\hline Kenya & $\mathbf{6 8 . 4}$ & $\mathbf{1 1 . 1}$ & $\mathbf{5 5 . 1}$ & $\mathbf{8 . 7}$ & $\mathbf{1 2 4 . 5}$ & $\mathbf{9 . 4}$ & $\mathbf{4 1 . 5}$ \\
\hline Rwanda & $\mathbf{5 2 . 2}$ & $\mathbf{8 . 5}$ & $\mathbf{2 0}$ & $\mathbf{3 . 1}$ & $\mathbf{7 2 . 5}$ & $\mathbf{5 . 8}$ & $\mathbf{1 5 . 8}$ \\
\hline Uganda & $\mathbf{8 4 . 1}$ & $\mathbf{1 3 . 7}$ & $\mathbf{1 1 5}$ & $\mathbf{1 7 . 9}$ & $\mathbf{1 9 9 . 1}$ & $\mathbf{1 3 . 8}$ & $\mathbf{1 7 . 2}$ \\
\hline Tanzania & $\mathbf{9 9}$ & $\mathbf{1 6 . 1}$ & $\mathbf{6 . 7}$ & $\mathbf{1}$ & $\mathbf{1 0 5 . 7}$ & $\mathbf{8 . 4}$ & $\mathbf{1 6 . 5}$ \\
\hline S-Sudan & $\mathbf{2 4 . 4}$ & $\mathbf{4}$ & $\mathbf{2 2 . 4}$ & $\mathbf{3 . 5}$ & $\mathbf{4 6 . 8}$ & $\mathbf{3 . 7}$ & $\mathbf{9 . 8}$ \\
\hline Sudan & $\mathbf{4 4 . 3}$ & $\mathbf{7 . 2}$ & $\mathbf{3 8 . 5}$ & $\mathbf{6}$ & $\mathbf{8 2 8}$ & $\mathbf{6 . 6}$ & $\mathbf{3 6}$ \\
\hline total & $\mathbf{6 1 6 . 1}$ & $\mathbf{1 0 0}$ & $\mathbf{6 4 3 . 9}$ & $\mathbf{1 0 0}$ & $\mathbf{1 2 6 0}$ & $\mathbf{1 0 0}$ & $\mathbf{1 7 7}$ \\
\hline
\end{tabular}

Source: 1- United States of America for international Development 2014.

2- UNICEF, United Nations Children Found.

3-USAID, United States Agency for International Development.

4-WHO, NMP Funding estimate 2019. 
GIS-Based for Mapping Malaria Ris...

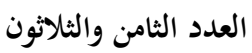

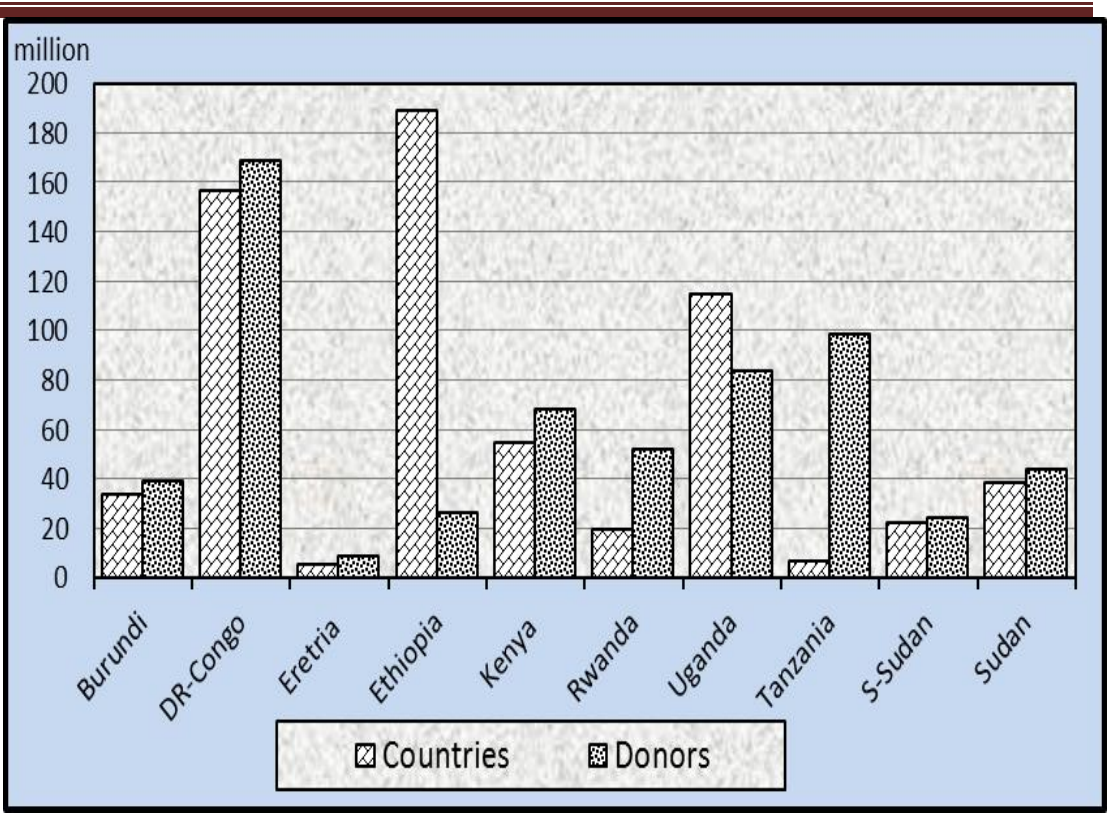

Figure (8)

The share infected case has 11.5 dollar.

- The donars has shared in the Malaria treatment expense with 616.1 million dollar and the contributor reported by countries has shared with 643.9 million dollar.

- The share of infected Malaria case from these contribution raised in Ethiopia, Eretria and Kenya because of the great center contribution from these governments and World Health Organization and other contribution.

- South Sudan has occupied the last rank for the share of infected Malaria case from the contribution because of 
the war what inside the country and the weakness of governmental authorities.

- The basin Nile countries need much money and many other contributor to face Malaria disease, that is cost too much money in establishing hospitals, constructing healthy units, saving pharmacies for accredited drug and training much people who works in the health community.

\section{Prevention and control strategies for malaria :}

Malaria will be one of the greatest dangerous of public health in the world generally and basing Nile region particularly. An estimated/ million new cases of malaria and malaria death occurd in the world occurd in 2018 with \%a curing in Africa region, with \% respectively, occring in the basin Nile region. Children under 5 years are especially susceptible to infection in the African and Nile basin region and estimated more than $70 \%$ of malaria death's happens in this age group.

(world malaria report, 2019)

The control of vector borne malaria disease represents one of the largest efforts from the global health challenges of the 21 th century.

Strategies which in Malaria controling and prevention : 


\section{A- Vector control:}

Aims to limit its ability to transfer the disease by prevention and keeping the region safe from malaria transmission, particularly the malaria depends on the vectoria ability of local vector population : this element in impacted by the climate, local ecology and the behavior of population to control main vector as the following :

\section{1-Insecticide - treated mosquito nets (ITNS).}

ITNS contain long-lasting insecticadal nets ( LLINS), where the in use cticide stay for more than 3 years, and nets conventionally treated, that make the insecticide is working for 12 months. Who encouraged the donor agencies to distribute (ITNS), particularly of small childrent and pregnant women (Who, 2007). Nearly more Than millions malaria cases of The Nlie basin population used (ITNS) that helped in reducing of child mortality of $18 \%$ in last 15 years. The Ownership of (ITNS) ranges between 34 and 96,6\% of hausehoeds at risk of malaria in The coutries of the Nile basin. (Lengeter,2014,p.22), also (ITNS) helped These countries in reduction of mortality in under five children of $23 \%$.An estimating $46 \%$ of the people at risk of malaria cannot sleep and Treated net in 2017 (Who 2017). Generally The possession ot (ITNs) rely on cost, socioeconomic, distribution locations and The distribution method because the residence has a low uptake in (ITNs) usage in sites which are in distance from the distribution sites. Most of the poor suffer from health weakness.

\section{8}




\section{2- Indoor residual spraying (IRS).}

The methodis concering a strategy of the world malaria That helped in the reduction of malaria burden in many countries in 2018 nearly 105 million were produced by (IRS) . Nowadays it expand in many areas in The Nile basin Region to control of epidmics especially in children aged 1 To 5years recently Uganda, 6 EThiopia, Kenya and D.Congo use The Irs. In spite of lts high cost but it less danger than using ng duchlorodlpheng trichlorethane (DDT). Some countries prevent Irs because of environmental hazards although it is recommended for use by WHO.

\section{3-larval breeding management (ISM)}

It deals with the aquatic habitat especially in the breeding site for mosquitoes to stop the completion of immature devlopment. Although it is an old tool in fighting Malaria in the reducing numbers of house and out doors mosquitoes. We can classify ISM as the following

- Habitat modification that help in changing of land and water including drainage ot surface water, land redamation

- Habitat manipulation, that often give aids in the water level manipulation, includes measures like drain clear and shading 
- Biological control :fighting of enemies when live in aquatic habitat, and this mathod needs organization from experts to use it

- larviciting by controling mosquitoes sites which fight or control of anopheline mosquito lirva in reducing adult mosquito growth.

- Most of the Nile basin countries used ISM in many sites is larvicting especially in the anon doned mines, (WHO, 2013).

\section{4- house improvement (HI)}

Houses are not only site where malaria Transmission happen but also became the the greatest Transmission environment in many endemic areas. Improved housing was thought to have rook part to prevent malaria as in Europe.

Data from demographic and health surveys indicates that malaria has reduce in 5 countries in the Nile countries and 22 countries in South Sahara of Africa between 2008 and 2015 because of modern housing that reduced malaria prevalence with 9 to $14 . \%$ in a comparison of traditional housing (centers for diseases, 2015). Housing improvements refers to the full screening of windows, doors and the high of cieling that aims to reduce mosquitoes that contact human indoors. 


\section{5- Attractive toxic sugar bait (ATSB)}

A new method that kill female and male mosquitoes. The ATSB method uses fruits or flower scent, sugar as a feeding and oral toxin to kill the different kinds of mosquitoes. It is sprayed on vegetation and the mosquitoes feeding toxin solution are killed. This method is suitable for keeping environment safe and cheap. A new study in the Nile basin countries showed 95\% reduction in female anpheles growth. (Muller, 2010, p67) from using (ATSB)

\section{6-Mass drug (MD)}

Mass drug, administration is the medication in the all countries with a curative dose of a drug without any testing for infection of symptoms ( centers for disease, 2016). These way was used since 1930s M.D a combination of sulphadoxinc pyrimethamine with IRS and it is used since 1969. Also the usage of prmaquine with chloroquine was given to many of the Nile basin population and succeeded.

Ivermeen is an endecatocide approved for the man usage a product of sreptomyces avermctinius, and used as drug. The advantages of this drug remains in the blood for nearly 7 days and make the blood toxic for malaria mosquitoes, This drug reduces the Anpheles mosquitoes that has feed on over meeting - treated indvidual. Also MD succeeded to reduce an Gambia more than $77 \%$ in its existence. The problem in M.D it is very costly and it is difficult in momadic society. 


\section{7- spraying the swarms}

By limiting the site's of mating swarms such wells, wood piles and grass. Spraying swarms with aerosols over 8-days period that reduced mosquito

\section{Table()}

\begin{tabular}{|l|l|l|l|l|l|}
\hline Country & $\begin{array}{l}\text { No. Of I. } \\
\text { lines }\end{array}$ & IRS & RDT & $\begin{array}{l}\text { Act } \\
\text { treatment }\end{array}$ & $\begin{array}{l}\text { W. Of malaria cases } \\
\text { treated with AC }\end{array}$ \\
\hline Burundi & 7.5 & 0.7 & 7 & 9.3 & 9.2 \\
\hline D.R Congo & 20.7 & 0.1 & 0.9 & 18.9 & 18.9 \\
\hline Ethiopia & 15.7 & 7.4 & 8.2 & 11.9 & .8 \\
\hline Kenyia & 1.8 & 2 & 4.2 & 7.2 & 5 \\
\hline Rwanda & 0.5 & 4.5 & 4.9 & 4.2 & 3.5 \\
\hline Eretria & 0.1 & 0.4 & 0.2 & - & .2 \\
\hline Uganda & 1.9 & 4.5 & 17.7 & 1.7 & - \\
\hline Tanzania & 7 & 3 & 26.1 & 16.4 & 6.3 \\
\hline $\begin{array}{l}\text { South } \\
\text { Sudan }\end{array}$ & 0.7 & 3.9 & 7.2 & - & - \\
\hline Sudan & 1 & 4.1 & - & 11.2 & - \\
\hline Total & 56.9 & 30.6 & 102.4 & 96.8 & 43.9 \\
\hline
\end{tabular}

Source:

An-Gambias density by $80 \%$ of 9 days especially in the female rate.

\section{8-live stock aiming}

Most of malaria vector species are feeding on lives stoks also the human : Direct treatment of calle spreading intensive insecticide that kill malaria at once. The best in using systemic veterinary insecticide that kill the mosquitoes. 
Also Ivermeetin has been tested in catlle and kill mosquitoes and made its life is short.

\section{spatial repellents.}

It has been studied for many years and succeeded in providing prevention in most of night. Also, the usage of coils, vaprization and impregnating mat may low the malaria risk at the household.

\section{Modification of mosquitoes gentie}

Through making mosquitoes unable to reproduce or breeding despite the long numbers of controlling tools tested against mosquitoes. The suitable way to control malaria in using integrated vector control (17), as a study was done in Tanzania from the combination of IRS and ITN that helped is reducing infection in the children and pregnant.

This combination of several vector helps to increase the efficacy, because the vector can be controlled in its different stages of life.

\section{Using pills}

Use the medicine prophylactic may prevent the disease but the person has to use wearing insects repellant, lwearing long sleeves and using a net in his sleeping bed.

This drug must be used from 1 to 4 weeks during the existence in the malaria prone area. 
Malaria is a major cause of death and its endemic varies from hypo-endemic to hyper-endemic in the Nile basin countries. Over $90 \%$ of cases are caused by infection with plasmodium falciparum. Anopheles arabinoses in the principle vector. Almost $75 \%$ of the total population are at risk of malaria (World Health Organization, 2019,) country cooperation strategy for WHO and the Nile basin countries2018). The annual estimated number of malaria episodes is 16.6 million. The dangerously of malaria represent in causing the death and absence from work in these countries. Nearly many thousand represent the main cause of morbidity and mortality. Annually, because of floods malaria constitutes 30-40 \% of all outpatient attendance, $20-25 \%$ of all hospital admission and $5-15 \%$ of all death. 


\section{- References}

- Afrahne YA., lowson BW., (2005), Effects of micro climatic changes caused by land use and land cover duration of gonotropic cycle of anopheles gambiae is wester Kenya highlands J. Med Entomal.

- Bruce Chwatt J. I., (1980), Essential malariology, London Heineman Medical books Ltd.

- Brabin B. J., Hakimi M., Pelletier D., (2001), An Analysis of anemia and pregnancy-Related Maternal Mortality, Journal of Nutrition Pub Med.

- Bradly, D.J, (1991), Morbidity and Mortality at Kenya and Tanzania, New York, Oxford, University Press

- Craig MH, Snow RW., (1999), A climate based distribution model at malaria transmission in subSaharan Africa, USA.

- Elissa N., Karch S., Bureaup and George AJ., (1994) "Ecology of larval mosquitoes, with special references to Anopheles arabiersis in market garden wells in urban cities of Dakar, Senegal. J. Med Entomol.

- FAO, (2010), state of the world, Rome.

- Fransworth NT., (1994), Ethopharmacology and drug development, wiley chichester. 
- Fedral Democratic Republic of Ethiopia, (2015), "The second growth and transformation plan, Addis Ababa; national planning commission.

- Guerra (2006), CA., snow RW., A Global assessment of chosen forests, deforestation and malaria risk, Ann trop Med parastiol.

- Grillet ME., (2000), Factors associated with distribution of anopheles aquasalis and anopheles oswaldoi in a 'alariaus area, northeastern venezucla. Med Entomal.

- Hay S.I., Cox J., Rogers S. J., and snow R.W.(2002), "climatic change and the resurgence of malaria in the east African, High lands nature, Pub Med.

- Kibret S., Wilson GG., Ryder D., (2015), the influence of dams Malaria transmission in sub-Sahara Africa, ecohealth.

- Malaney P. sachs J., (2000), the Malaria Gap. American journal of tropical Medicine and Hygiene, New York.

- Marsh k., Snow R.W., (1999), Malaria Transmission and Morbidity parasitological, Rome.

- Solomon Kibert, Jonthan Lautze and G., Glenn Wilson, (2016), Malaria and large dams in sub-Saharan Africa; Future impacts in a changing climate, biomed central. 
- Snow RW, Marshk, Sueur D., le. (1996), The need for map of transmission intersity to guide Malaria control Africa parasitol.

- Samson Wakuma, Nicodemus Mandere and Goran Ewald, (2009), floods and health in Gambella Region, Ethiopia: a quantative assessment of strengths and weakness of capping mechanism Global Health Action, vol:2.

- Steketee RW., Nahlen BL., Parise ME., Menedez, C., (2000), The burden of malaria in pregnancy in malariaendemic areas. Am J Trop Med Hyg.

- The World Bank: Ethiopia, climate Risk fact sheet.

- United Nation, (2010), Road map towards the implementation of the United Nation Millennium Declaration, Report of the secretary general.

- United Nation population Division, (2011), world population prospected: (2010), Revision and World Urbanization, prospected: http://esa.un.org/unpp.

- United Nations: Sudan: floods 27 July, (2007), office for the coordination of humanitarian affairs. Relief Webor 1 August, (2007), www.relief.int. Vincent Robert, Kate Macintyre, and John C., (2003), BEIER': Malaria Transmission in urban sub-Saharan African, New York, Trop Med, Hya. 
- World Bank Development Report, 2001, Attacking poverty Washington, DC: World Bank.

- Wernsdorfer WH., MC., Greger ,I., (1989), Malaria: Principles and practice of malariology, London: Churchil linvigstonez.

- WHO (2018), The consequences of reducing plasmodium falciparum transmission in Africa Genva.

- World Malaria report, (2019), A great highlights of the current Malaria burden and in malaria presentation.

- WHO. Worldwide Malaria distribution in, (2015), public Health mapping Group, World Health Organization; Geneva, (2015).

- World Malaria Report, (2019), A great highlight of the current Malaria burden and in Malaria prevention.

- WHO, insecticide. Treated mosquito net. WHO position statement, Geneva: World Health Organization, 2007.

- Zimmeman, R.H., Galardo, A.K., and Wirtz, R., (2006), Blood meal hosts of anopheles spices in malariaendemic in Brazilian amazon, journal of medical Entomology, 43.

- Zarif C., lumsdon AE., Bedkamp J.A., (2015), global boom in hydropower dam construction. Aqua science. 
- Zhou G., Minakawa, N., Cotheko AK., (2004), Association between climate variability and malaria epidemic in the east African highlands. Proc Natl Acad Sci, USA. 